\title{
Review \\ What Flips the Switch? Signals and Stress Regulating Extraintestinal Pathogenic Escherichia coli Type 1 Fimbriae (Pili)
}

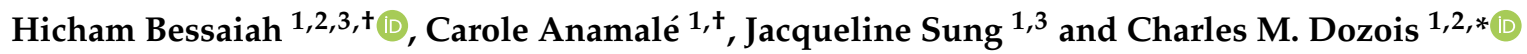 \\ 1 Institut National de Recherche Scientifique (INRS)-Centre Armand-Frappier Santé Biotechnologie, Laval, \\ QC H7V 1B7, Canada; hicham.bessaiah@inrs.ca (H.B.); carole.anamale@inrs.ca (C.A.); \\ chia-ling.sung@mail.mcgill.ca (J.S.) \\ 2 Centre de Recherche en Infectiologie Porcine et Avicole (CRIPA), Saint-Hyacinthe, QC J2S 2M2, Canada \\ 3 Department of Microbiology and Immunology, McGill University, Montreal, QC H3G 0B1, Canada \\ * Correspondence: charles.dozois@inrs.ca \\ + These two authors contributed equally as primary authors.
}

Citation: Bessaiah, H.; Anamalé, C.; Sung, J.; Dozois, C.M. What Flips the Switch? Signals and Stress Regulating Extraintestinal Pathogenic Escherichia coli Type 1 Fimbriae (Pili). Microorganisms 2022, 10, 5. https://doi.org/10.3390/ microorganisms10010005

Academic Editors: Vincenzo Scarlato and Davide Roncarati

Received: 8 November 2021

Accepted: 15 December 2021

Published: 21 December 2021

Publisher's Note: MDPI stays neutral with regard to jurisdictional claims in published maps and institutional affiliations.

Copyright: () 2021 by the authors. Licensee MDPI, Basel, Switzerland. This article is an open access article distributed under the terms and conditions of the Creative Commons Attribution (CC BY) license (https:// creativecommons.org/licenses/by/ $4.0 /)$.

\begin{abstract}
Pathogens are exposed to a multitude of harmful conditions imposed by the environment of the host. Bacterial responses against these stresses are pivotal for successful host colonization and pathogenesis. In the case of many E. coli strains, type 1 fimbriae (pili) are an important colonization factor that can contribute to diseases such as urinary tract infections and neonatal meningitis. Production of type 1 fimbriae in E. coli is dependent on an invertible promoter element, fimS, which serves as a phase variation switch determining whether or not a bacterial cell will produce type 1 fimbriae. In this review, we present aspects of signaling and stress involved in mediating regulation of type 1 fimbriae in extraintestinal E. coli; in particular, how certain regulatory mechanisms, some of which are linked to stress response, can influence production of fimbriae and influence bacterial colonization and infection. We suggest that regulation of type 1 fimbriae is potentially linked to environmental stress responses, providing a perspective for how environmental cues in the host and bacterial stress response during infection both play an important role in regulating extraintestinal pathogenic E. coli colonization and virulence.
\end{abstract}

Keywords: Escherichia coli; stress response; type 1 fimbriae; adhesion

\section{Introduction}

The survival of microorganisms is highly dependent on their ability to adapt to a frequently changing environment and to respond to a variety of environmental cues. When important environmental changes occur, bacteria need to rapidly respond and adjust through complex transcriptional or post-transcriptional regulatory mechanisms [1]. Regarding bacterial pathogens, this adaptation is an important feature for survival and proliferation during colonization in different host anatomical niches that may represent distinct microenvironments. Escherichia coli is one of the best known and most studied freeliving organisms. Pathogenic E. coli is commonly grouped into two broad categories: E. coli causing intestinal-type infections (InPEC) and those causing extraintestinal-type infections (ExPEC) [2]. This group of E. coli strains are phylogenetically and epidemiologically distinct from strictly commensal strains and other pathovars that cause intestinal diseases [3]. The ExPEC group brings together several pathotypes. Uropathogenic E. coli (UPEC) causes urinary tract infection (UTI) inducing cystitis, pyelonephritis, bacteremia, and sepsis. E. coli causing neonatal meningitis (NMEC) is responsible for meningitis in newborns [4,5]. Avian pathogenic E. coli (APEC) are the cause of avian colibacillosis, which manifests itself in various pathologies including aerosacculitis, pericarditis, perihepatitis, peritonitis, and sepsis [6]. These pathovars are a common cause of systemic infections in animals including humans [7-9]. Although ExPEC strains often possess and share many virulence strategies, 
the population genetics of clones belonging to ExPEC are also quite diverse [10]. ExPEC have a variety of virulence-associated traits, although there is no common set of genes responsible for ExPEC virulence, and many factors including the host background and immune status can contribute to disease outcome. During the infection process, the genomewide transcriptional response of ExPEC during colonization of the host has provided insight into genes and virulence factors that may contribute to adaptation, such as iron and heme import systems, toxins, adhesins, lipopolysaccharides, invasins, capsules, and antibiotic resistance genes. These genes are encoded on mobile genetic elements, such as bacteriophages, transposons, plasmids, or in specific regions called Pathogenicity Islands, which are frequently found in ExPEC [8,11]. The structure of the E. coli genome consists of a flexible gene pool (including virulence genes) and a conserved part, which is also called the "core genome". This core genome has been preserved throughout its vertical evolution, with very limited intragenomic rearrangement, resulting in the conserved synteny that is apparent today $[12,13]$.

For pathogenic bacteria, the ability to adhere to host tissues is the initial step of infection. Adhesins are key virulence factors as they mediate interactions with host cells or mucosa and promote bacterial colonization and infection. Adhesion is even more important during infection where microenvironmental stresses such as changes in $\mathrm{pH}$, osmolarity, temperature, and mechanical forces are encountered. ExPEC are able to express a large variety of adhesins such as $\mathrm{P}$ fimbriae, curli fimbriae, or type 1 fimbriae, with different receptor specificities [14]. For example, UPEC can express more than 10 different types of fimbriae, particularly the UPEC strain CFT073 has at least 12 distinct fimbriae and several afimbrial adhesins $[12,15]$. This spectrum provides the bacterium with the capacity to bind to a range of different target molecules; however, fimbriae are important immunogenic factors and therefore, bacteria have no interest in expressing more than one at the same time. During colonization, their expression is subject to "regulatory crosstalk", which allows bacteria to express the appropriate fimbriae at the right time [16]. As an example, Snyder and others have demonstrated that in a UTI, when type 1 fimbriae are overexpressed in vivo, P fimbriae expression is downregulated. In addition, in the UPEC strain CFT073 expressing neither type 1 fimbriae nor P fimbriae, FIC fimbriae expression was increased [17]. In some literature, fimbriae may also be referred to as pili. Both terms can be designated to adhesins [18]. However, in this review, the long filamentous non-flagellar structures allowing bacterial adhesion to cells are referred to as fimbriae, whereas the term "pili" is reserved for $\mathrm{F}$ or conjugative pili involved in bacterial mating [14,19].

\section{Role of Type 1 Fimbriae in Pathogenesis}

One of the most important virulence factors of pathogenic E. coli is type 1 fimbriae. This fimbrial adhesin can mediate bacterial attachment to and invasion of host cells and is subject to regulation through phase variation by a variety of environmental signals. More specifically, bacterial attachment via type 1 fimbriae to host D-mannosylated proteins will trigger signal transduction and induce actin rearrangement in target cells, allowing the pathogen to invade. In UPEC, type 1 fimbriae bind to the mannose-enriched uroplakins found on urothelial cells of the bladder [12]. Once internalized, the bacteria can rapidly multiply to form biofilm-like intracellular bacterial communities (IBCs) where they can evade host immune defenses and antibiotic treatments. As they proliferate, bacteria can then disperse from IBCs to colonize and invade other cells. IBC formation mediated by type 1 fimbriae is especially important for UPEC pathogenesis as it promotes bacterial ascension from the urinary tract to the kidneys [20]. Although the role of type 1 fimbriae has mainly been studied in UPEC, the fimbrial adhesins have also been shown to contribute to NMEC pathogenesis through adherence and invasion of human brain microvascular endothelial cells (HBMEC) [21]. In APEC strains, type 1 fimbriae are associated with survival, fitness, and pathogenesis by allowing more colonization of the trachea and the lung [22,23].

The following sections will present the current state of knowledge for general and specific regulators of stress known in ExPEC and the impact of type 1 fimbriae regulation. 


\section{Type 1 Fimbriae}

\subsection{Type 1 Fimbriae Biogenesis}

Fimbriae (pili) are long, proteinaceous organelles that extend from the surface of many bacteria and mediate diverse functions, including attachment, invasion, and biofilm formation. In Gram-negative bacteria, fimbriae are assembled via a range of different protein translocation systems, including the chaperone-usher (CU) pathway, the type IV secretion pathway, and the extracellular nucleation precipitation pathways [24].

Chaperone-usher fimbriae (CUF) are morphologically characterized as being relatively thick ( $\sim \mathrm{nm}$ diameter), rod-like fibers with a length varying between 0.2 and $2 \mu \mathrm{m}$ [25]. CU fimbriae are comprised of multiple copies $(>1000)$ of the major fimbrial subunit and a tip adhesin that is linked by an adapter complex, which often consists of multiple minor subunit proteins [26]. Fimbrial subunits are shuttled through the inner membrane to the periplasm by the general secretory pathway, SecYEG translocon [27]. These subunits are then linked together via a zip-in zip-out mechanism coordinated by periplasmic chaperone proteins and a pore-forming usher protein, which acts as a scaffold for subunit assembly [28]. The chaperone facilitates several essential steps in the pathway; it mediates the folding of fimbrial subunit proteins, prevents their polymerization in the periplasm, and directs their passage to the usher. The usher in turn acts as an assembly platform and facilitates the assembly of the fimbrial structural organelle (structural component of a fimbria). Briefly, the $N$-terminal extension on an incoming fimbrial subunit displaces the beta-strand of the chaperone protein bound to the previously assembled subunit. Through this mechanism of strand exchange, fimbrial subunits are rapidly polymerized to form fimbriae [29].

Fimbrial adhesins, which are often located at the tip of the organelle, typically recognize specific receptor targets in a lock-and-key fashion, thus enabling the bacterium to target a specific surface and display tissue tropism.

\subsection{Genetic Organization of Fimbrial Gene Clusters and Transcriptional Regulation}

Type 1 fimbriae are among the most common adhesins in E. coli and are encoded by the fim gene cluster [30]. Nine genes encode the structural components and specific transport systems (fimAICDFGH), and the regulatory genes (fimB and fimE) [30-32]. FimA is the major structural subunit, which forms the majority of the extracellular filament. FimC and FimD are the chaperone and the usher, respectively, that facilitate the transport of the subunits to the bacterial surface. FimH, the adhesin tip, is integrated into the organelle structure with the help of adaptors, FimF and FimG. Although fimI is part of the operon, its function/role remains unknown; however, it is required for biogenesis of fimbriae [33-37].

The expression of type 1 fimbriae is governed by the orientation of a $314 \mathrm{bp}$ invertible element (the fim switch), located immediately upstream of the major subunit gene and flanked by two 9 bp inverted repeats (5' TTGGGGCCA) [34]. The expression of type 1 fimbriae is phase-variable, meaning that the promoter located within an invertible element (IE) fimS can switch between two different orientations. The phase-ON orientation (fimbriated phenotype) of the IE allows transcription of fimA and other accessory genes, resulting in the expression of type 1 fimbriae. When fims is in the opposite orientation, no type 1 fimbrial transcription occurs, and bacteria are phase-OFF (type 1 fimbriae-negative). The inversion of the element is mediated by two site-specific recombinases, FimE, which primarily promotes switching from phase-ON to phase-OFF, and FimB, which can mediate switching in either direction [31,38].

One of the earliest phenotypic characterizations of type 1 fimbriae was their ability to confer D-mannose-sensitive hemagglutination of guinea pig erythrocytes [12,39]. Further characterization of the type 1 tip adhesin, FimH, demonstrated that type 1 fimbriae recognize mannose, which is found on the surface of many types of host cells.

\section{Regulators of Stress Responses and Type 1 Fimbriae in ExPEC}

The stress response can be defined as the change in gene expression of bacteria for an optimal environmental adaptation. These changes can be controlled by a specific sigma 
factor (e.g., master regulator, heat shock response) or another transcriptional regulator (e.g., SoxR/S or OxyR), a two-component system, the nutritional starvation response (the stringent response), or small RNAs [40]. These regulators can mediate changes in bacterial gene expression to adapt to stress. Some affected genes are implicated in virulence, such as type 1 fimbriae. As type 1 fimbriae play a key role in mediating E. coli host colonization and virulence, it is important to understand the regulation of these fimbriae in relation to stress responses. Indeed, numerous regulators (Figure 1) and growth conditions (Figure 2) have been identified that can affect the production of type 1 fimbriae. Below we present regulators that can play important roles in global stress regulation but have also been shown to affect expression of type 1 fimbriae (Tables 1 and 2).

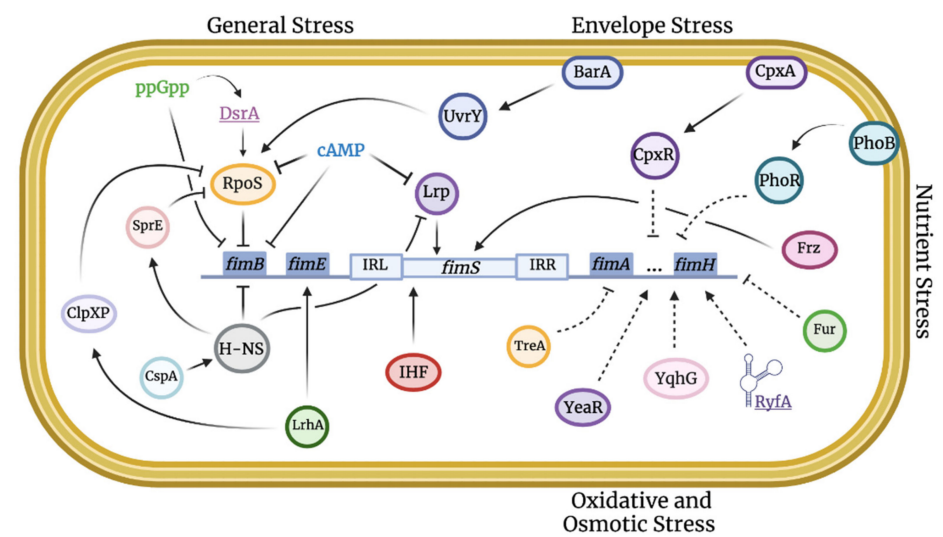

Figure 1. Integration map of stress-induced pathways implicated in type 1 fimbriae regulation. Stress regulation can be linked to virulence, such as the expression of type 1 fimbriae, through an intrinsic network of direct and indirect pathways. Solid lines indicate confirmed stimulatory or inhibitory effects. Dashed lines indicate unclear mechanisms that remain to be elucidated.

Table 1. Global and specific stress response regulators involved in virulence and virulence gene expression in Escherichia coli.

\begin{tabular}{|c|c|c|c|}
\hline Regulator & Stress Response & Role in Virulence & Reference \\
\hline RpoS & Nutrient deprivation & Master regulator of stress & [41] \\
\hline H-NS & Temperature & $\begin{array}{l}\text { Regulates flagellar gene expression and fim and pap } \\
\text { operon and many other genes }\end{array}$ & [42] \\
\hline Lrp & Nutrient deprivation & Required for fim and pap fimbriae & [43] \\
\hline ppGpp & Stringent response & Involved in biofilm formation and production of flagella & {$[44,45]$} \\
\hline cAMP & Nutrient deprivation & $\begin{array}{c}\text { Required for acid stress response, regulation of multiple } \\
\text { virulence factors }\end{array}$ & [46] \\
\hline SoxS/R and OxyR & Oxidative stress & Required for virulence in UPEC & [47] \\
\hline CpxRA & Membrane damage & Required for type 1 and P fimbriae expression in UPEC & [48] \\
\hline \multirow{4}{*}{ sRNA } & \multirow{4}{*}{ Diverse } & MicF regulates gene expression for the outer membrane & [49] \\
\hline & & RyhB is required for nutrient stress/iron homeostasis & {$[50]$} \\
\hline & & GadY is required for acid stress resistance & [51] \\
\hline & & $\begin{array}{l}\text { RyfA is required for survival in human macrophages, } \\
\text { resistance to multiple stresses }\end{array}$ & [52] \\
\hline $\mathrm{RpoH}$ & Heat shock & Regulates gene expression in heat shock & [53] \\
\hline
\end{tabular}



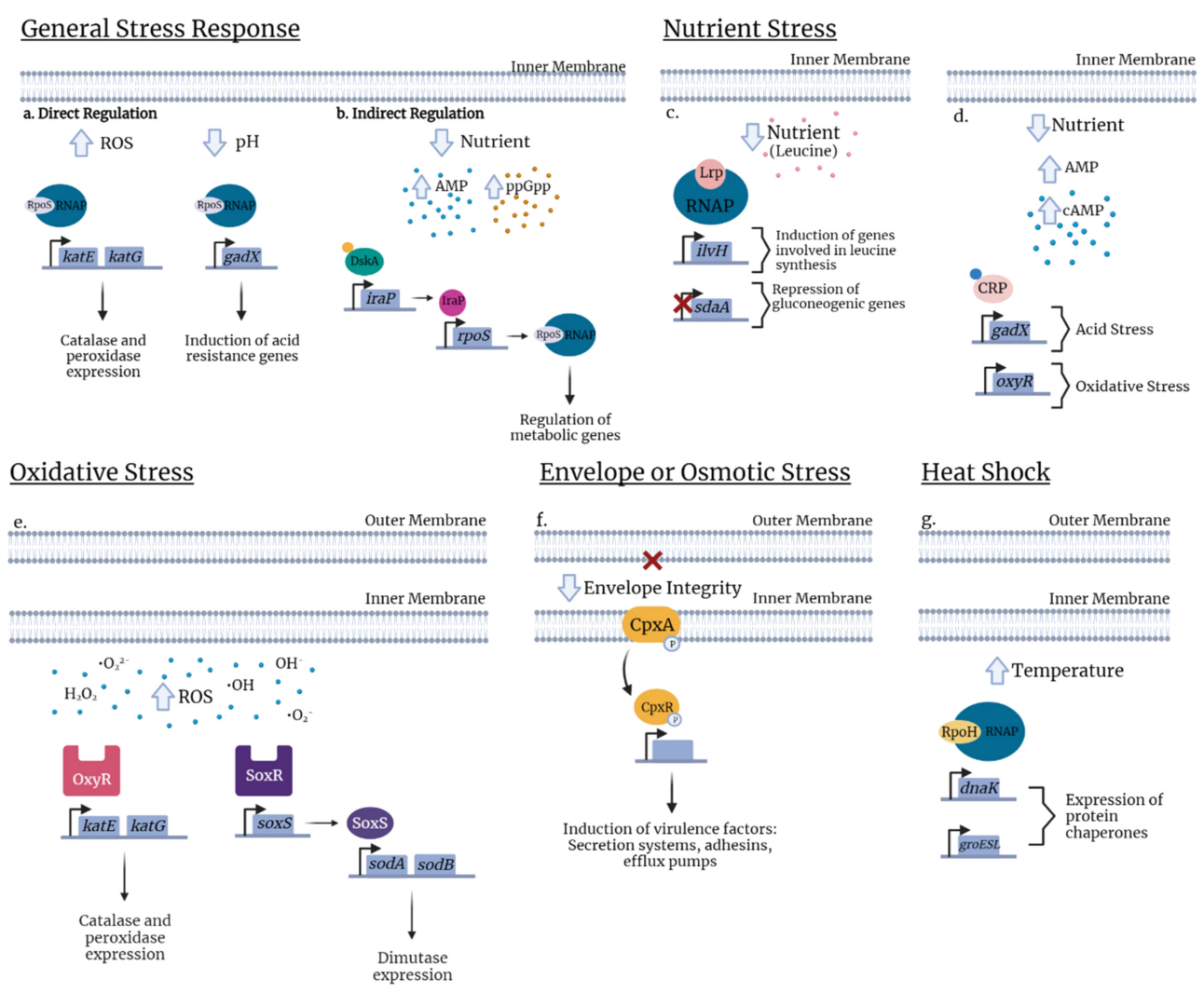

$\underline{\text { Heat Shock }}$

Figure 2. Examples of stress regulators in E. coli. General stress response. (a) In response to oxidative stress, RpoS occurs in direct regulation by binding to RNA polymerase (RNAP) and recognizes the promoter thus allowing expression of $k a t G$ and $k a t E$ catalase and peroxidase expression. Likewise, in response to low $\mathrm{pH}$, binding of RpoS to RNAP induces expression of the transcriptional regulator, gadX. (b) Under nutrient limitation, RpoS is indirectly regulated by the transcription factor DskA or by the alarmone ppGpp (orange circle) that leads to the augmentation of the anti-adaptor IraP and releases RpoS to activate stress gene expression. Nutrient stress. (c) Under nutrient deficient conditions, a mis-regulation of cAMP signaling for nutrient availability allows binding of cAMP to the cAMP Receptor Protein (CRP) which activates the protein and specific binding with target DNA sequences regulating the expression of genes involved in acid stress ( $\mathrm{gadX}$ ) or in oxidative stress (oxyR). (d) In nutrient deprivation, exogenous leucine (pink circle) influences the Lrp regulon and modulates Lrp directly. Presence of leucine concentrations represses the transcription of the $i l v H$ promoter whereas in the absence of leucine, $i l v H$ is directly activated by Lrp. Inversely, leucine releases Lrp to bind to the $s d a A$ promoter and activates its expression. Oxidative stress. (e) In response to oxidative stress due to excess levels of prooxidants $\left(\mathrm{H}_{2} \mathrm{O}_{2}, \mathrm{O}_{2}, \mathrm{OH}\right)$, depending on whether the stress is mediated, bacteria respond by two regulatory systems, the peroxide regulon (OxyR) or the superoxide regulon (SoxR/S). OxyR activates genes involved in catalase and peroxidase expression ( $k a t E$ and $k a t G)$. When oxidized, the sensor SoxR activates soxS transcription resulting in expression of superoxide dismutase ( $\operatorname{sod} A$ and $\operatorname{sod} B)$. Envelope stress. (f) The two-component system consists of the inner membrane, the sensor histidine kinase (CpxA) and the cytoplasmic response regulator CpxR. Envelope stress conditions lead to phosphorylation of CpxA which transfers the phosphate group to $\mathrm{CpxR}$. Phosphorylated CpxR-P functions as a transcriptional regulator which controls the expression of numerous genes including some virulence factors. Heat shock. (g) In a simple pathway, during temperature upshift $\left(30{ }^{\circ} \mathrm{C}\right.$ to $\left.42{ }^{\circ} \mathrm{C}\right)$, the Heat Shock Response (HSR) is induced by the increase of RpoH levels, primarily due to an enhanced translation of rpoH mRNA and stabilization of the protein. The elevated temperature disturbs protein homeostasis and induces accumulation of misfolded proteins. Chaperones DnaK and GroEL/S which are proteins helping to activate or degrade $\mathrm{RpoH}$ and regulate heat shock gene transcription. 


\subsection{General Stress}

RpoS (Sigma S, $\sigma S$ ): The sigma factor oS (also called RpoS or $\sigma 38$ ) is one of the most studied global regulators of the general stress response (Table 1). The oS-mediated general stress response can be defined as the induction of various mechanisms to prepare bacterial cells for increased stress conditions, including toxicity and stress due to population density during culture, acidity, oxidative, and osmotic stresses, often described as the stationary-phase stress response [54,55]. Bacterial gene transcription requires RNA polymerase (RNAP) which binds to a dissociating $\sigma$ factor $(\sigma)$ to initiate the transcription process. Alternative $\sigma$ factors also exist and are often linked to specialized regulators that are activated during growth transitions, morphological changes, or under specific stress conditions (nitrogen metabolism, heat shock, iron-limitation) [56]. In E. coli, RpoS is considered the master regulator in the general stress response [41]. The rpoS gene, which encodes $\sigma S$, regulates, directly or indirectly, at least 500 genes (more than $10 \%$ of the E. coli genome) implicated in survival during the stationary phase and resistance to stress. Although RpoS can be considered as a master general regulator, regulation of RpoS is also influenced by other regulators $[57,58]$. For example, Girard and others have shown that the synthesis of $\sigma S$ is positively influenced by the transcription factor, DskA, and its cofactor, the ppGpp alarmone (Figure 2) [59].

Although one of the main adaptations to environmental conditions involving RpoS is the transition from exponential growth in a nutrient-rich environment to the stationary phase, which can lead to accompanying nutrient-deficient conditions, RpoS is also critical for regulation of oxidative stress and expression of catalase, e.g., kat $G$ and katE in E. coli (Figure 2) [60]. For instance, during urinary tract infection, oS is required for UPEC strain CFT073 to withstand phagocyte-mediated oxidative stress [61] and acid stress via expression of $\mathrm{gadX}$ (Figure 2) [62]. RpoS also plays a role in UPEC via its involvement in the biosynthesis of the signal molecule, c-di-GMP, promoting the production of adherence and cell-aggregating factors including type 1 fimbriae while reducing cellular motility by repressing the production of flagella $[63,64]$. RpoS is directly involved in regulating the expression of virulence factors in other ExPEC such as strains responsible for neonatal meningitis. In meningitis strain E. coli $\mathrm{K} 1$, RpoS contributes to invasion of brain microvascular endothelial cells [65].

Regarding type 1 fimbriae, RpoS is activated as bacteria enter the stationary phase and represses fimB transcription by potentially affecting its promoter (Table 2). In E. coli K-12, by repressing fim $B$ transcription (Figure 1), all bacterial cells will gradually turn off type 1 fimbrial expression. Specifically, it was demonstrated that RpoS mutants did not have type 1 fimbrial repression during the stationary phase. Further, rpoS mutants had an accelerated phase variation frequency; and this is most likely due to the increased expression of fimB [66]. However, other studies have demonstrated that fim $A$ expression stays relatively high during the stationary phase, a contradicting result to the ExPEC fimbrial repression by RpoS $[67,68]$. Similarly to RpoS, H-NS is also highly growth-phase dependent and even though both belong to their own independent pathways, H-NS demonstrates some regulatory function over RpoS. Zhou and others have demonstrated that H-NS indirectly activates SprE, a response regulator that is part of the RpoS degradation pathway. Further, H-NS mutants have an increase in RpoS stability. In other words, H-NS reduces RpoS levels which may have an indirect effect on type 1 fimbriae regulation [69].

LrhA: LrhA is a transcriptional regulator of the LysR family involved in flagellar motility and fimbrial genes. Regarding type 1 fimbriae, LrhA indirectly affects fimS phase variation by promoting fimE transcription (Table 2). By analyzing quantitative RT-PCR results, Blumer and others have demonstrated that levels of fimE transcripts decrease in LrhA mutants, leading to increased type 1 fimbrial expression. Further investigation showed that even though LrhA can bind to promoter regions of fimA, fimB, and fimE, it has the highest affinity for the fimE promoter and only directly affects fimE transcription. In other words, these results suggest that LrhA represses type 1 fimbrial expression by promoting fimE transcription [73]. Interestingly, LrhA also functions as a regulator of RpoS. 
More specifically, it promotes RpoS degradation by affecting the activity of the protease, ClpXP [87]. Therefore, LrhA also indirectly links environmental stress and the expression of type 1 fimbriae through modulation of the RpoS network.

Table 2. Example of regulators of type 1 fimbriae in ExPEC involved in stress resistance.

\begin{tabular}{|c|c|c|c|c|c|}
\hline Regulator & Switch & FimE & FimB & Effect on Fim Expression & Reference \\
\hline \multicolumn{6}{|c|}{ General and specific stress regulators } \\
\hline IHF & Switching on fimS & & & Positive or negative $^{1}$ & [70] \\
\hline Lrp & & $+/-$ & $+/-$ & Positive or negative $^{1}$ & [71] \\
\hline H-NS & & - & $\begin{array}{l}<37^{\circ} \mathrm{C}:- \\
>37^{\circ} \mathrm{C}:+\end{array}$ & $\begin{array}{l}<37^{\circ} \mathrm{C} \text { : Negative } \\
>37^{\circ} \mathrm{C} \text { : Positive }\end{array}$ & {$[72]$} \\
\hline RpoS & & & - & Negative & {$[66]$} \\
\hline LrhA & & + & & Negative & [73] \\
\hline ppGpp & & & - & Negative & [67] \\
\hline cAMP & & & - & Negative & [68] \\
\hline \multicolumn{6}{|c|}{ Envelope stress } \\
\hline CpxR-P & Regulates the inversion & & - & Negative & [74] \\
\hline BarA/UvrY & Reduction of fimA & Unknown & & Unknown $^{1}$ & [75] \\
\hline \multicolumn{6}{|c|}{ Oxidative and osmotic stress } \\
\hline TreA & & Unknown & Unknown & Positive & [76] \\
\hline YeaR & & Unknown & Unknown & Positive? ${ }^{1}$ & [77] \\
\hline IbeA & & $+?$ & $+?$ & Positive? ${ }^{1}$ & [78] \\
\hline YqhG & & Unknown & Unknown & Positive? ${ }^{1}$ & [79] \\
\hline RyfA & & Unknown & Unknown & Positive? ${ }^{1}$ & [52] \\
\hline \multicolumn{6}{|c|}{$\begin{array}{l}\text { Nitrosative stress } \\
\end{array}$} \\
\hline Fim $X$ & & Unknown & Unknown & Positive? & {$[80]$} \\
\hline \multicolumn{6}{|c|}{ Nutrient limitation and oxygenation } \\
\hline \multicolumn{6}{|l|}{ Pst and } \\
\hline $\begin{array}{l}\text { Pho } \\
\text { regulon }\end{array}$ & \multirow{4}{*}{ Increased fim $A$} & + & - & Negative & [81] \\
\hline Frz & & Unknown & Unknown & Positive & [82] \\
\hline Fur & & & Unknown & Positive & [83] \\
\hline Oxygenation & & Unknown & Unknown & Positive & [84] \\
\hline \multicolumn{6}{|c|}{ Biofilm and quorum sensing } \\
\hline $\begin{array}{l}\text { Effect of } \\
\text { salicylate } \\
\text { on marA }\end{array}$ & & & - & Negative & [85] \\
\hline QseC/B & & Unknown & Unknown & Positive & [86] \\
\hline
\end{tabular}

${ }^{1}$ Putative role.

H-NS: The histone-like nucleoid structuring (H-NS) protein is a major component of the enterobacterial chromosome with roles in many biological processes. H-NS is known to modulate the expression of at least 200 genes in E. coli [88-90]. Since H-NS mostly affects transcription negatively, this protein is considered a transcriptional repressor (Table 1) $[90,91]$. In addition to a repressor role at the transcriptional level, studies have shown that H-NS can exert a positive and negative effect at the post-transcriptional level and influences bacterial virulence [72]. H-NS mainly negatively regulates genes whose expression is influenced by environmental factors, such as temperature (including cold and heat-shock), oxygen availability, osmolarity, growth phase, or $\mathrm{pH}[90,92,93]$. For example, it has been shown that hns mutants have an improved chance of survival under extremely acidic conditions and increased transcription of the global regulator, RpoS [69,94,95].

In pathogenic $E$. coli, the relationship between temperature and H-NS regulation has been studied in the control of specific genes associated with virulence traits including 
motility, toxin production, pathogenicity island-associated genes, or fimbriae (pili) $[96,97]$. For example, H-NS positively affects the synthesis of flagella, by interacting directly with the $f l h D C$ regulatory region [42]. At low temperatures, the H-NS protein was shown to repress transcription of fimbrial operons, including the fim and the pap operon [98,99].

Regarding the fim operon, H-NS may have a direct effect on promoter switching. Studies have shown that H-NS can bind to DNA segments adjacent to fimS [68]. However, the indirect pathway of which H-NS regulates phase variation is better understood. Generally, H-NS represses fimS switching by repressing fimB and fimE expression (Figure 3). The protein potentially binds to fimB and fimE promoters, which can either block RNA polymerase from binding or prevent the latter from properly functioning (Figures 1 and 3) [97]. Different studies have shown with H-NS mutants that H-NS regulates genes required for stress resistance and that different environmental conditions can affect H-NS expression [100]. However, it remains unclear how these conditions affecting H-NS influence type 1 fimbrial expression. Interestingly, Olsen and others demonstrated with strains that constitutively express H-NS, that when the temperature was increased from 30 to $37^{\circ} \mathrm{C}$, fimE promoter activity reduced (less OFF-phase cells) whereas fimB promoter activity increased (more ON-phase cells) [72]. The difference in fim expression may be due to the higher affinity of H-NS to the fimB promoter (Table 2). In other words, at a lower temperature, H-NS expression is induced by the cold-shock protein, CspA, indicating a higher expression of $\mathrm{H}-\mathrm{NS}$ and higher repression of fimB, resulting in fewer ON cells. These results suggest that H-NS favors type 1 fimbrial expression at mammalian body temperature, indicating that $\mathrm{H}-\mathrm{NS}$ is able to sense the optimal environment and respond to these signals. Further, H-NS affects the Lrp pathway by repressing Lrp expression. Not only were hns null mutants found to have an increased type 1 fimbrial expression, but they also had an increased level of Lrp [101]. Therefore, induction of H-NS expression could lead to an antagonized Lrp expression, which decreases fim phase variation frequency.
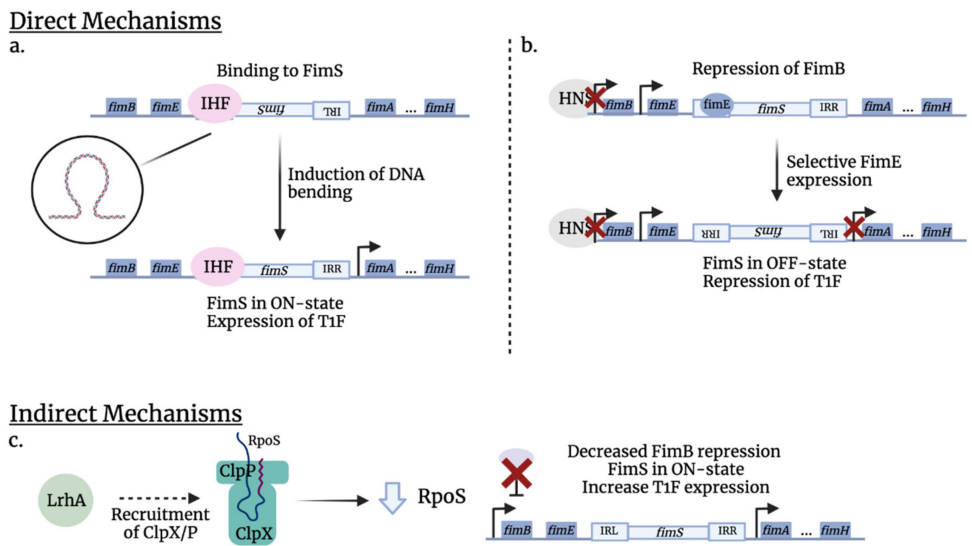

Figure 3. Mechanisms of action of stress regulators on type 1 fimbriae expression. (a) Regulators can bind directly to fimS to influence phase variation. For example, IHF binds to regions of fimS to induce a sharp DNA bend that facilitates the recombination of the fim switch. In nutrient-deprived environments, such as when bacteria enter the stationary phase, IHF expression will be induced, increasing phase variation, and influencing type 1 fimbriae expression. (b) Regulators can block recombinase expression to influence fimS phase variation. In the case of $\mathrm{H}-\mathrm{NS}$, the regulator can bind to the FimB promoter to block its expression, resulting in more FimE production. Since FimE facilitates phase variation of fimS in the OFF-state, type 1 fimbriae will be repressed. This is a simplified model of regulation by H-NS as the latter binds to both FimB and FimE promoters. (c) Other regulators may be indirectly linked to stress by influencing direct stress regulators. Although LrhA can act directly on type 1 fimbriae and flagellar gene expression, it is indirectly linked to stress via the RpoS network. LrhA recruits ClpX/P protease complex through an unknown mechanism (dotted arrow), leading to reduced RpoS production. As a result, FimB repression decreases and more fimS is found in the ON-state, which increases type 1 fimbriae expression. 
Lrp: The leucine-responsive regulatory protein (Lrp) is an abundant regulatory protein that usually links bacterial metabolism to environmental signals, especially in nutrientdeficient conditions [102,103]. More specifically, growth in nutrient-poor medium leads to higher expression of $l r p$, which can act as a global regulator to activate transcription of genes that are part of the Lrp regulon. (Table 1). Depending on the target, effects can be potentiated, repressed, or unaffected by the level of exogenous leucine $[43,104]$ (Figure 2). Although activation or repression by Lrp can be potentiated by leucine, Lrp-mediated regulation can also occur independently of the presence of leucine [105].

In E. coli, Lrp regulates $\approx 400$ genes of which over 200 genes are involved in direct interactions with target DNA sequences. Indeed, Lrp has been shown to regulate $\approx 10 \%$ of all ORFs in E. coli $[103,106,107]$. In order to survive in various environments while avoiding energy loss, E. coli must respond to environmental changes, such as nutrient levels, by regulating the transport of amino acids. Lrp does so by regulating the expression of many amino acid exporters. Indeed, due to limited nutritional resources, bacteria must stop replication and enter the stationary phase [102,108,109]. Further, Lrp also regulates the production of many types of fimbriae, including pap-encoded $\mathrm{P}$ fimbriae and fimencoded type 1 fimbriae [43]. Similarly to IHF, Lrp is another site-specific DNA-binding protein that promotes both fimB- and fimE-mediated phase switching (Figure 3). Mutants that have defective Lrp or modified binding sites demonstrated lower phase-switching frequencies. In type 1 fimbriae, leucine potentiates Lrp activity, resulting in more phase variation (Table 2) [102]. Upregulation of Lrp occurs when bacteria are found in a nutrientdeficient environment, which is dependent on the bacterial growth phase. Its expression tends to increase as bacteria enter the stationary phase, where nutrient levels gradually diminish [110]. Therefore, nutritional stress will result in upregulation of Lrp, which will then stimulate phase variation. Interestingly, the presence of other amino acids such as alanine, isoleucine, and valine were found to potentiate Lrp activity in fimB- and fimEmediated phase switching of type 1 fimbriae production [71].

IHF: The integration host factor (IHF) is a heterodimeric site-specific DNA-binding protein, composed of an IHF $\alpha$ subunit and an IHF $\beta$ subunit [70]. IHF responds to environmental changes, more specifically, when bacteria enter the stationary phase or find themselves in a nutrient-deficient environment [111]. Regarding the fim switch (Table 2), IHF induces a sharp bend that facilitates the formation of a synapse between the inverted repeats, creating a recombination-promoting structure. This structure allows a more efficient phase switching (Figure 3). Additionally, IHF was found to bind to DNA segments adjacent to and within the fim switch. When these binding sites were mutated, leading to a lower affinity of IHF, the phase-switching frequency decreased dramatically as well. These results indicate that IHF acts directly on phase variation and when the bacteria are in starving conditions, an increased expression of IHF will promote fimS switching, in whichever orientation that favors bacterial survival (the exact orientation remains unclear) [70].

ppGpp: The small nucleotides (p)ppGpp, also called alarmones, are a term related to two nucleotides: ppGpp and (p)ppGpp. This guanosine penta- and tetraphosphate is the effector molecule of the well-known stringent response, which was first described in 1996 [112] and represents a general bacterial stress response [113,114]. During nutrient starvation (Table 1), the accumulation of ppGpp allows bacterial cells to readjust their metabolism and physiology to slow down growth. The accumulation of ppGpp plays a role in response to various stressful signals including osmotic shock, temperature variation [115], oxidative conditions, or pH downshift [116]. The molecule also takes part in biological processes, such as biofilm formation [44], antibiotic resistance [115], production of surface organelles such as flagella [45], and as previously mentioned, the general stress response [117].

In E. coli, when the amino acid levels become limiting for growth, ppGpp binds to RNA polymerase (RNAP). This interaction causes downregulation of stable RNAs (rRNA and tRNA), restricting protein synthesis [118-122]. Additionally, studies have shown that the accumulated alarmone can influence the transcription of $\approx 500$ genes [123,124]. During the 
stringent response, type 1 fimbriae-encoding gene expression is down-regulated. Indeed, ppGpp disrupts fimB transcription by affecting activity at one of the three fimB promoters (Figure 1), leading to a decrease in type 1 expression (Table 2). Aberg and others have demonstrated that ppGpp mutants showed almost no yeast agglutination, indicating an absence of type 1 fimbriae production. In addition, using a fimA-lacZ fusion, it was shown that fim transcription levels were also dramatically reduced [67].

c-AMP: The 3', 5'-cyclic adenosine monophosphate (cAMP) is a ubiquitous molecule present in both prokaryotes and eukaryotes [125-127]. The cAMP receptor protein (CRP) is the target for cAMP signaling and is also capable of regulating genes involved in the catabolism of secondary carbon sources [68,128]. cAMP was initially described for its role in mediating the 'glucose response', or carbon catabolite repression (CCR) $[129,130]$. In bacteria, this term is related to a regulatory mechanism that allows a specific and important utilization of carbohydrates. In addition to its known role in metabolic regulation, cAMP has an extended function in global gene regulation. A misregulation of cAMP signaling for carbon availability can affect expression of key virulence influencing host colonization [131].

In E. coli, the CAMP-CRP complex serves as a global transcriptional regulator of the expression of $\approx 200$ genes [132]. CRP also can play a role in acid stress response, when during exponential growth in rich medium, it can repress the RpoS-dependent gad gene transcription and contribute to bacterial survival in acidic environments $[46,62,133]$. Further, intracellular cAMP levels affect the transcription of OxyR, a regulator contributing to the response against oxidative stress (Figure 2) [134,135] or intracellular cAMP levels can also be modulated by external osmolarity $[136,137]$. Interestingly, the effects of cAMP signaling are often amplified by cAMP-mediated co-regulation of other global regulators such as RpoS [138]. Generally, cAMP-CRP mutants are attenuated due to their hypersensitivity to reactive nitrogen species and inability to utilize a number of carbon sources such as lactose or amino acids. However, these mutants are highly resistant to hydrogen peroxide and acid stress and in a way, have a greater survival advantage. In fact, cAMP-CRP mutants had an increased expression of RpoS, which led to an increase in the production of catalase to respond to environmental stress. In other words, cAMP participates in the regulatory pathway of RpoS by repressing its transcription and therefore also indirectly regulates type 1 fimbrial expression [139].

With regard to the direct effect on production of type 1 fimbriae, CRP-cAMP represses fimB-mediated recombination (Table 2). Mutants that were fimB proficient demonstrated an increased population of Fim-ON cells in the absence of CRP-cAMP; however, in mutants that were fimE proficient, no significant differences were observed [68]. In both regulatory pathways, the high concentration of cAMP, indicating nutrient deprivation, led to the repression of type 1 fimbriae.

Furthermore, Muller and others have demonstrated that CRP-cAMP modulates gyrA (DNA gyrase). The study showed that CRP mutants had lower gyrA expression and gyrase activity, which may explain the repression of fimB-mediated recombination. In fact, CRP-cAMP mutants had similar levels of fim-ON cells as bacteria treated with novobiocin, a DNA gyrase inhibitor. There are also other factors, such as Lrp (see above), that aid with the recombination of fimS. In CRP mutants, Lrp levels were found to be increased. Potentially, due to the decreased expression and activity of DNA gyrase in crp mutants, Lrp is up-regulated to compensate for the loss [68]. In summary, CRP-cAMP is able to regulate type 1 fimbriae expression by indirectly regulating the RpoS and Lrp pathways as well as by directly modulating DNA gyrase activity that potentially affects fimB-mediated recombination.

Regulation by sRNAs: Bacterial small regulatory RNAs (sRNAs) are commonly 50 to 500 nucleotides long and are involved in various stress responses to environmental changes including those to overcome membrane damage, $\mathrm{pH}$ variations, and oxidative stress. In fact, sRNAs mediate the regulation of regulatory proteins by affecting their transcription or their activity. Mechanisms employed by bacterial sRNAs can be divided into two categories: the cis-encoded sRNAs, which are coded by the complementary DNA strand of their 
mRNA targets, and the trans-encoded sRNAs which are located remotely from their mRNA targets and often exhibit only partial complementarity to them. The well conserved Hfq protein chaperone is required as a cofactor for these RNA-RNA interactions to facilitate sRNA stabilization [140-142]. Regulation by Hfq can lead to an upregulated expression by remodeling inhibitory RNA structures or blocking access of negative regulators such as RNases or Rho but can also downregulate expression by recruiting Rnases [143]. Therefore, a given sRNA can have various mRNA targets and can carry both positive and negative regulatory roles. Likewise, an individual mRNA can be a target of multiple sRNAs. This is the case of RpoS whose expression is regulated by at least three different sRNAs: OxyS, DsrA, and RprA.

The genome of E. coli comprises at least 90 sRNAs of which a large number is implicated in bacterial virulence [144]. Several sRNAs are involved in membrane stress [49]. sRNAs also play a role in nutrient stress response, such as RyhB, which is an sRNA expressed under iron-starvation conditions and is regulated by the Fur protein [145]. In UPEC, RhyB facilitates the synthesis of many iron-scavenging siderophores including enterobactin, salmochelin, and aerobactin, further suggesting its role as a virulence mediator of UTI in animal models [50]. Regarding pH stress, the Hfq-dependent GadY sRNA is mostly involved in acid stress resistance in E. coli (Table 1) [51]. Recent work on the sRNA RyfA from UPEC strains revealed its roles in resistance to oxidative and osmotic stresses and survival in human primary macrophages. RyfA will be further discussed in later sections [52].

RpoH (б32) and Heat shock (HS): The heat shock response (HSR) is defined as a cellular response to sustain protein homeostasis and promote heat resistance in eukaryotic and prokaryotic cells [146-148]. Thus, elevated temperature or other environmental cues that disturb protein homeostasis induce the accumulation of misfolded proteins and lead to the transcription of genes encoding heat shock proteins (HSPs) such as DnaK/DnaJ and GroEL/GroES chaperones (Figure 2) [149-151]. In E. coli, the HSPs are regulated by rpoH which encodes the alternative sigma factor, $\sigma 32(\mathrm{RpoH})$ [152]. In E. coli, HSR is induced by a shift from $30^{\circ} \mathrm{C}$ to $42^{\circ} \mathrm{C}$ through transcription of heat shock genes (hsp) which are regulated by this temperature upshift (Table 1). RpoH initiates the transcription of $\approx 90$ genes [53]. DnaK plays a role in the pathogenicity of multidrug-resistant bacteria such as in E. coli K-12 W3110. A dnaK mutant showed a strong susceptibility to fluoroquinolones [153]. However, the regulation of heat shock genes is complex and still needs to be clarified.

\subsection{Envelope Stress}

CpxRA two-component system: In Gram-negative bacteria, the bacterial envelope is an important interface between the bacterial cell and the often stressful extracellular environment [154]. This complex envelope protects bacteria from harsh conditions and must be able to endure stresses such as acidic or basic $\mathrm{pH}$, antimicrobial cationic peptides, bile, perturbations caused by misfolded proteins, and alterations in phospholipids and lipopolysaccharides [155]. The bacterial envelope integrity is mostly dependent on Envelope Stress Responses (ESRs) which can sense the presence of extracellular stress and the disruption of homeostasis in the periplasm. The ESRs are regulated by two-component systems (TCS) which include the Bae, Rcs, and Cpx systems, or by RNA polymeraseassociating alternative sigma factors [156,157].

In E. coli, the best characterized ESRs are regulated through the alternative sigma factor $\sigma \mathrm{E}$ (response to stress in outer membrane/periplasm) and the TCS system CpxRA (response to stress in the inner membrane) (Table 1) [158]. Interestingly, the CpxRA pathway mediates the transcription of genes involved in cell adhesion, biofilm formation, and antibiotic resistance (Figure 2) $[159,160]$. Further, the pathway mediates the regulation of the expression of genes involved in surface structures associated with bacterial virulence such as type three secretion systems (TTSS) or adhesive organelles and fimbriae [48].

In APEC strain MT78, Matter and others have demonstrated with cpxA mutants that the system negatively affects type 1 fimbrial expression. However, the double cpxRA mutants showed type 1 fimbriae expression similar to the wild-type levels. This result 
indicates that CpxR-P is directly bound to the fimA promoter region leading to a phase-OFF orientation (Table 2) [74]. Conversely, in zebrafish and murine models and cpxRA mutants from UPEC strains UTI89 and CFT073, the deletion of the cpxRA operon led to decreased colonization of the murine bladder and reduced virulence [161]. At this point, there is a possible link between the Cpx envelope stress response and type 1 fimbriae expression, but the fim operon has not been reported to be directly regulated by CpxR in these UPEC strains.

BarA/UvrY: In E. coli, the TCS BarA/UvrY controls carbon metabolism, flagella, and biofilm formation by regulating the activity of CsrA. In the APEC strain $\chi 7122$, a bar $A$ or $\operatorname{uvr} Y$ mutant demonstrated reduced fimA expression (two-fold compared to the wildtype) [75]. Further, BarA/UvrY TCS is also known to regulate RpoS. The study done by Herren and others, shows evidence for decreased transcription of rpoS in $\operatorname{bar} A$ and $u v r Y$ mutants. This repression leads to a down-regulation of the pst operon, ref [162] whose inactivation in UPEC strains has also been reported to reduce transcription and production of type 1 fimbriae [81]. Therefore, it appears that BarA/UvrY is a global regulator in APEC strains, which can indirectly affect type 1 fimbrial expression by regulating the rpoS gene (Figure 1); however, the exact link between BarA/UvrY and regulation of type 1 fimbriae remains unclear.

OmpA: Teng and colleagues highlighted the potential role of the outer membrane protein A (OmpA) in the NMEC strain E. coli $\mathrm{K} 1$. Therefore, due to its importance to maintain the integrity of the bacterial outer membrane structure, loss of OmpA could induce an envelope stress response. Studying yeast agglutination and expression of fim gene, it has been shown that, in vitro, omp $A$ deletion in $E$. coli $\mathrm{K} 1$ decreased the expression and production of type 1 fimbriae. Further, in in vivo experiments, omp $A$ mutants exhibit reduced ability to bind and invade HBMEC. However, this decrease may not be completely due to diminished type 1 fimbrial expression. Although the role of type 1 fimbriae in the pathogenesis of meningitis E. coli remains to be clarified, this study suggests that OmpA and type 1 fimbriae potentially contribute to E. coli K1-associated meningitis [163].

\subsection{Osmotic and Oxidative Stress}

Oxidative stress can be described as an excess of cellular prooxidants. Oxygen molecules such as superoxide $\left(\mathrm{O}_{2} \bullet^{-}\right)$, hydrogen peroxide $\left(\mathrm{H}_{2} \mathrm{O}_{2}\right)$, hydroxyl radical $(\bullet \mathrm{OH})$, nitric oxide (NO), and other oxygen-derivative intermediates that can modify organic molecules are referred to as reactive oxygen species (ROS). Oxidative stress is caused by bacterial respiratory activity or by toxic molecules released by host cells. Host phagocytes can generate RO, exerting antimicrobial activities against a broad range of pathogens [155,164,165].

A number of studies have demonstrated a link between osmotic stress and type 1 fimbriae, some of which have been contradictory. The discrepancies observed may be due to regulatory differences in strains used in experiments as well as the variability in composition of urine samples. For example, Schwan et al. demonstrated in UPEC strain NU149 that osmotic stress caused by $\mathrm{NaCl}$, and acidic conditions induced a decrease in type 1 fimbriae expression [166]. By contrast, Snyder et al. demonstrated that UPEC strain CFT073 had an increased level of type 1 fimbriae expression during UTI [167]. Further, Withman et al. also showed that type 1 fimbriae expression by strain in CFT073 increased under osmotic stress due to an increase in urea whereas increased $\mathrm{NaCl}$ concentration had no effect on levels of type 1 fimbriae [168]. Conversely, a report by Greene and colleagues showed that UPEC strain UTI89 had decreased expression of type 1 fimbriae in human urine [169].

SoxS/R and OxyR: The oxidative stress response is mainly mediated at the transcriptional level through two major regulatory systems, OxyR and SoxRS (Table 1) [170]. These two transcriptional regulators belong to different families. OxyR, a LysR family transcriptional factor, regulates genes that play a role in the removal of hydrogen peroxide, whereas SoxRS regulates genes that target superoxides and nitric oxides [171-174]. The OxyR protein is composed of a regulatory domain, which senses $\mathrm{H}_{2} \mathrm{O}_{2}$ concentrations, and a DNA-binding domain that can directly control gene expression. The SoxRS system 
includes a redox sensor/regulator, SoxR, and a second regulator, SoxS which subsequently regulated $\approx 100$ genes that help bacteria withstand $\mathrm{O}_{2}{ }^{-}$products [170].

E. coli uses the SoxRS and OxyR systems to resist stress caused by high levels of ROS (Figure 2). Members of the SoxRS regulon control the expression of mainly the superoxide dismutases $\operatorname{sod} A$ and $\operatorname{sodB}[175]$. Additionally, the OxyR regulon induces the transcription of genes that increase resistance to hydrogen peroxide, including $k a t G$ and kat $E$ (catalase), ahpCF (alkylhydroperoxide reductase), and $d p s$ (iron sequestration) [176,177]. SoxRS regulon also regulates genes that modify lipopolysaccharide (LPS) in the cell envelope of E. coli, which affects its resistance against antibiotics [178]. Likewise, in UPEC, inactivation of oxyRS leads to an increased susceptibility to $\mathrm{H}_{2} \mathrm{O}_{2}$, ref [179]. Deletion of oxyRS in the wild-type UPEC strain E. coli Ecla and CFT073 resulted in decreased resistance to $\mathrm{H}_{2} \mathrm{O}_{2}$ and decreased virulence in a mouse model of ascending UTI [47]. Although SoxRS and OxyR have not been reported to influence type 1 expression, their pathways share intermediary factors that are implicated in type 1 fimbriae regulation, suggesting they may exert an indirect effect on type 1 fimbriae as well.

TreA: TreA encodes a periplasmic trehalase which hydrolyzes trehalose, a key osmoprotectant molecule in bacteria. In line with the link of osmotic stress to the expression of type 1 fimbriae, Pavanelo et al. reported that deletion of treA from ExPEC strain MT78 leads to an increase in osmotic resistance to urea as well as a decrease in expression of type 1 fimbriae. Loss of TreA also led to reduced colonization of the uroepithelium in a murine UTI model [76].

YeaR: Recent studies have shown that yeaR, encoding a protein of unknown function, could have a direct influence on the formation of intracellular bacterial communities (IBCs) by UPEC strain UTI89. Interestingly, yeaR, an uncharacterized gene, is overexpressed in IBCs. Conover et al. have shown that a yeaR mutant of UTI89 also has decreased fim expression (Figure 1). Type 1 regulation is linked to changes in oxidative stress via YeaR, which can potentially induce a yet-identified stress regulator that directly influences fimS switching [77].

Other cytoplasmic and periplasmic proteins: IbeA (invasion of brain endothelium) is encoded by the GimA genomic island present in some E. coli strains. The role of GimA in the pathogenesis of newborn meningitis and ExPEC is well characterized. Recent studies showed that in an APEC strain BEN2908, a ibeA mutation caused a decrease in the expression of the fim $B$ and fimE recombinases and reduced expression of type 1 fimbriae [78]. Further, IbeA is involved in resistance to oxidative stress of pathogenic E. coli strains by increasing $\mathrm{H}_{2} \mathrm{O}_{2}$ resistance [180]. It is likely that IbeA plays a role in modulating type 1 fimbriae expression through oxidative stress; however, the mechanism remains unclear. Similarly, we recently demonstrated that in UPEC strain CFT073, YqhG, a predicted periplasmic protein contributes to virulence in the urinary tract inducing a decrease in the production of type 1 fimbriae. In addition, this protein is involved in resistance to oxidative stress (Figure 1) [79].

Small RNA RyfA: Another aspect of oxidative resistance has been demonstrated with the small RNA $r y f A$. As previously discussed, $r y f A$ is involved in the regulation of resistance to oxidative and osmotic stresses and its deletion reduced UPEC survival in human macrophages. RNA-seq analysis revealed that genes involved in survival or virulence were downregulated in a ryf $A$ mutant in addition to multiple operons encoding fimbriae. In the mouse UTI model, inactivation of ryfA in UPEC strain CFT073 showed a decrease in urinary tract colonization. The $r y f A$ mutant also had reduced production of type 1 (Figure 1). Taken together, the results suggest that $r y f A$ may play a key regulatory role in UPEC adaptation to oxidative and osmotic stress. The specific contribution that this small RNA plays in the regulation of type 1 fimbriae is currently unknown (Table 2) but studies are in progress to determine the pathways and the mechanisms of how ryfA acts on fim switching [52]. 


\subsection{Nitrosative Stress}

Prior studies have identified FimX as a DNA invertase (Fim-like family member associated with ExPEC) that regulates fim expression in the urinary tract by mediating the phase OFF to ON transition [181]. FimX is also an epigenetic regulator of a LuxR-like response regulator, HyxR. More specifically, FimX epigenetically regulates the expression of $h y x R$ via bidirectional phase reversal of its promoter region at sites different from the fim promoter. In addition, the expression of HyxR leads to a suppressed tolerance and survival in the presence of reactive nitrogen intermediates (RNI). The ability of UPEC UTI89 to survive RNI-mediated stresses in macrophages depends on the proper regulation of HyxR, which acts as a negative regulator of RNI response pathways. In the study done by Bateman et al., it was observed that HyxR could repress the expression of a bacterial nitric oxide detoxification enzyme and therefore resist nitrosative stress [80]. Furthermore, FimX produces unidirectional phase inversion of the fimS promoter, preventing the expression of type 1 fimbriae. These observations suggest that FimX may be important for mediating the inversion of both the fimS and hyxR promoters. In summary, FimX may coordinately regulate crosstalk between nitrosative stress resistance and phase variation of fimbriae to promote virulence.

\subsection{Nutritional Stress and Metabolism}

The Pst system and the Pho regulon: Phosphate, mostly inorganic phosphate (Pi), is implicated in several chemical reactions such as signal transduction by TCS. When phosphate is nutritionally limited (extracellular concentrations $<4 \mu \mathrm{M}$ ), $\mathrm{Pi}$ is transported by the Pst (for phosphate-specific transporter) system. The pst operon, pstCAB-phoU encodes an $\mathrm{ABC}$ transporter. This system has two clearly defined functions: (i) fixation of $\mathrm{Pi}$ and (ii) detection of Pi which regulates the expression of the Pho regulon. The Pst system is part of the Pho regulon, which is controlled by the TCS, PhoB/R [182]. Members of the Pho regulon are expressed under phosphate-deficient conditions but are repressed in a phosphate-enriched environment. In addition to its role in metabolism, Lamarche and colleagues have demonstrated that inactivation of the Pst system constitutively activates PhoB / R and attenuates virulence in a murine model [183]. In addition, inactivation of the pst system inhibited the expression of type 1 fimbriae in both APEC and UPEC strains [182,184]. Indeed, the $p s t$ mutant of UPEC strain CFT073 showed a decreased expression of the fimA structural gene which correlated with differential expression of genes encoding recombinases fimB, fimE, ipuA, and ipbA (Figure 1) [81].

Frz: In the APEC strain BEN2908, a genomic region involved in carbohydrate metabolism and transcribed in one operon called the $f r z$ operon was identified. The frz operon appears to be involved in the survival of the BEN2908 strain in LB medium during the late stationary growth phase under oxygen-restricted conditions. Results revealed that deletion of frz results in reduced production of type 1 fimbriae. Further, amplification of the fimS switch showed that the OFF orientation was increased in the mutant compared to the wild-type strain (Figure 1). In all, the frz operon plays a role in survival of ExPEC under stressful conditions such as oxygen and nutrient restriction and can contribute to virulence by promoting the expression of type 1 fimbriae [82].

One of the most important types of nutrient limitation in the host environment is metal limitation. Sequestration of metals by the host immune system has been termed "nutritional immunity", since the availability of metals, such as iron and zinc, is required for microbial growth [155,185].

Fur: In bacteria, iron homeostasis is under the control of positive and negative regulators. Among these factors, the Fur (Ferric Uptake Regulator) transcription factor is highly conserved in many bacterial species. Fur represses genes encoding proteins involved in iron uptake and iron-dependent metabolic enzymes in an iron-rich environment. In UTIs caused by UPEC, a deletion of fur did not attenuate virulence. More specifically, the bacterial load of the fur mutant in the bladder was similar to that of the wild-type strain. Interestingly, the deletion of fur in the UPEC strain CFT073 results in increased adhesion and invasion 
of bladder epithelial cells in vitro [50], due to increased fim $A$ expression and production of type 1 fimbriae (Figure 1). The absence of fur also led to increased IBC formation and the expression of $f l i C$, a gene that contributes to bacterial motility. In fact, in iron-rich conditions, Fur protein is directly bound to the region upstream of fim $A$ and $f l i C$, resulting in a reduction of type 1 and flagellar gene expression. In summary, during UTI, bacteria are under restricted-iron conditions therefore, the Fur protein should remain inactive allowing expression of type 1 fimbriae, flagellar genes, and genes involved in biofilm formation [83].

\subsection{Biofilm Formation}

Effect of salicylate on biofilm formation and relationship with MarA (UPEC): MarA is an $\mathrm{AraC} / \mathrm{XylS}$ transcriptional regulator that can repress or activate genes. For example, MarA is an activator of tolC and ompX. Salicylate represses the binding of MarR to the region of the mar operon. MarR proteins are members of the Multiple Antibiotic Resistance Regulator family of transcriptional regulators. This inhibition results in an increased production of MarA and a decreased accumulation of antibiotics that is associated with reduced production of $\mathrm{OmpF}$ and $\mathrm{OmpC}$ outer membrane porins and a concomitant increase in the production of the AcrAB multidrug efflux pump. In UPEC strain HC91255, RT-PCR and protein analyses showed that in the presence of salicylate, marR mutant strains overexpress mar $A$ and downregulate fim $A$ and fim $B$ expression and type 1 fimbriae production. The reduced production of recombinases leads to decreased production of type 1 fimbriae and biofilm formation [85].

Biofilm and oxygen conditions: UPEC are facultative anaerobic pathogens with great metabolic diversity. Previous studies have shown that deleting genes encoding enzymes in the tricarboxylic acid (TCA) cycle reduced virulence. The TCA cycle generates molecules such as NADH and FADH, which can be used in the electron transport chain if oxygen or one of the five alternative terminal electron acceptors (ATEA) is available. Further, UPEC mutants that are unable to use oxygen as a terminal electron acceptor seem to have attenuated virulence. These observations suggest that UPEC strain UTI89 uses aerobic respiration in the urinary tract.

As mentioned before, type 1 fimbriae are largely involved in biofilm formation, and indeed, reduced production of type 1 fimbriae also results in decreased biofilm formation on abiotic surfaces [186]. Indeed, in UPEC strain 536, regulation of type 1 fimbriae by LrhA has also been proven to influence biofilm formation [73]. Interestingly, Eberly et al. reported that fim expression is reduced in the total absence of $\mathrm{O}_{2}$ in UPEC UTI89 [84]. Mutants incapable of aerobic respiration also exhibit a defect in type 1 fimbriae production and biofilm formation, suggesting that anoxic conditions reduce the formation of biofilm due to decreased levels of type 1 fimbriae. Since E. coli uses ATEAs when $\mathrm{O}_{2}$ is not available, biofilm formation could have theoretically been restored under anaerobic conditions in the presence of these ATEAs; however, this was not the case. $\mathrm{O}_{2}$ was demonstrated to be the terminal electron acceptor that allows the most robust biofilm formation. Potentially, $\mathrm{O}_{2}$ improves biofilm production since bacteria find themselves in ideal conditions to proliferate and persist, suggesting that the bladder is an ideal environment for biofilm formation by UPEC strains [84].

The link between the TCS QseC/B and quorum sensing in the formation of IBCs: Common studies have established that the TCS, QseB/C, can respond to quorum sensing and is also involved in pathogenesis. Generally, QseC phosphorylates QseB (the response regulator) which leads to increased transcription of virulence genes [187]. In UPEC strain UTI89, analyses of single deletions of QseB/C demonstrated that a qseC mutant is reduced in the formation and maturation of IBCs, while a double deletion of $q s e B C$ or a single deletion of $q s e B$ has no impact on pathogenesis. Interestingly, in the absence of QseC, QseB remains constitutively active which leads to a downregulation of type 1 fimbriae expression. To further confirm the importance of QseC in type 1 fimbriae expression, PCR analyses of fimS demonstrated that in the qseC mutant, fimS was mostly oriented in the OFF phase. However, the interplay between QseB and QseC is more complex than a simple TCS. QseC 
has a dual role as a bifunctional sensor kinase/phosphatase by dephosphorylating QseB and restoring levels of type 1 fimbriae production. In summary, $\mathrm{QseB} / \mathrm{C}$ is an example of a detection system of quorum sensing which is involved in IBC formation and expression of type 1 fimbriae [86].

\subsection{Physical Cues and Regulation of Type 1 Fimbriae}

So far, specific regulatory proteins affecting the expression of type 1 fimbriae have been described. However, fimbrial components and lectin-mediated adherence can also contribute to the production of type 1 fimbriae. Schwan and others have demonstrated that the binding of the FimH adhesin leads to a positive feedback loop by comparing fim gene expression in the presence of mannose-coated Sepharose beads and normal Sepharose beads. More specifically, when analyzing transcripts, in the presence of mannose-coated beads, levels of fimB transcripts increase and levels of fimE transcripts decrease, which explains the overall increase in type 1 fimbriae expression. Type 1 expression levels were decreased when the FimH binding pocket was mutated, suggesting that the binding of the fim $H$ gene product can indirectly regulate phase-switching. Interestingly, in UPEC strains, the percentage of $\mathrm{ON}$ cells persisted even in an acidic environment ( $\mathrm{pH}$ 5.5) whereas in the wild-type strain, the percentage dropped significantly [188]. In this case, it is suggested that virulence contributes to the ability of bacteria to adapt and withstand environmental stresses. Conversely, a lower $\mathrm{pH}$ environment has been described to decrease type 1 fimbriae expression [189]. Moreover, a study done by Tchesnokova and others has shown that the binding of FimH to an antibody raised against its lectin domain leads to an increase in mannose-specific binding, resulting in increased adhesion to the uroepithelium. This result further demonstrates that the regulatory activity of FimH binding may play a role in eliciting an immune response that enhances virulence [190]. In fact, studies have demonstrated that the FimH adhesin is an important inducer of the innate immune response, specifically activating natural killer cells, by binding to toll-like receptor 4 [191,192].

\subsection{Shear Stress}

Up to now, different chemical and physiological stresses have been discussed, but physical or mechanical stresses can also play a part in the regulation of adherence and type 1 fimbriae. Shear stress is caused by fluid flow which generates frictional forces. In UPEC, adherent bacteria need to withstand the flow of urine in order to remain attached and colonize the uroepithelium. Therefore, type 1 fimbriae and biofilm formation are important for resistance to mechanical stress. As mentioned in previous sections, fimbriated bacteria can form multi-layered colonies or biofilms as they multiply. Studies have demonstrated that biofilm formation provides significantly greater resistance to shear stress. The outer layer potentially acts as a protective barrier for underlying cells within the biofilm, allowing most bacteria to remain adherent, and their membranes remain intact. Mutants lacking type 1 fimbriae were not able to form biofilms and therefore, could not resist shear stress [193]. Interestingly, Thomas and others have demonstrated that mannose-coated surfaces have a stronger level of FimH-mediated bacterial binding/attachment as shear stress force increases, suggesting that FimH binding may be force-activated or force-enhanced [194]. Although it is unknown whether shear stress has a direct effect on fimbrial transcription or expression, this result still demonstrates that mechanical stress promoted by shear forces, which can be a physiological defense against bacterial infection, may actually promote FimH-mediated adherence and potentially favor increased expression of these fimbriae due to FimH lectin binding.

\section{Link between Stress and Type 1 Fimbriae in Non-Pathogenic E. coli}

Since type 1 fimbriae are also frequently produced by non-pathogenic E. coli, regulation of these fimbriae has often been investigated in E. coli K-12. For instance, studies showed different effects of temperature or growth medium on type 1 fimbriae. More 
specifically, growth in glucose inhibits type 1 fimbriae [195], while expression of fimB is regulated by $\mathrm{N}$-acetylglucosamine (NagC regulator) and $\mathrm{N}$-acetylneuraminic ( $\mathrm{NanR}$ regulator) [196]. Growth in minimal medium at a high temperature $\left(42{ }^{\circ} \mathrm{C}\right)$ increases FimB-mediated switching while FimE-mediated switching is favored in rich medium at low temperature $\left(28^{\circ} \mathrm{C}\right)$ [71]. Moreover, acetylphosphate (AcP) plays an important role during aerobic growth in excess of carbon and during mixed acid fermentation. Wolfe and colleagues demonstrated that AcP positively regulates genes required for assembly of type 1 fimbriae. Interestingly, the Fe-S metalloregulatory protein, IscR modulates gene expression in response to the iron-limiting environment as well as oxidative stress. In E. coli K-12 strain MG1655, analyses suggest that IscR, represses type 1 fimbriae expression by regulating fimE [197]. Further research done by McVicker and colleagues highlighted that the SlyA protein acts as an activator of type 1 fimbriae expression by inducing fimB expression [198]. Concerning inflammatory response, a release of sialic acid can be recognized by $E$. coli as an indicator of inflammation and the latter can suppress fimB expression through the binding of NanR affecting the phase variation of fimS from ON to OFF [199]. It is likely that such regulatory mechanisms may also apply to type 1 fimbriae of some pathogenic E. coli strains, although it is important to consider that regulation of type 1 fimbriae can involve numerous players and can vary considerably among different strains or pathotypes.

\section{Conclusions}

In summary, the regulation of type 1 fimbriae is complex, and involves not only a wide range of regulators, but also specific environmental cues. As there are many signals, bacteria need different systems to respond specifically to different cues or stresses. E. coli strains have developed intricate regulatory pathways in order to acquire specificity in their adaptation to environmental conditions and that can affect control of type 1 fimbriae expression which is ultimately mediated by the orientation of an invertible ON/OFF promoter-containing switch. Less optimal environments can impose stresses that can alter the levels of type 1 fimbriae production. By having many regulatory pathways associated with regulation of type 1 fimbriae, a combination of responses can lead to alterations in the levels of expression of type 1 fimbriae. Since most regulators cause changes in expression of multiple genes, broad-range regulation may then need to be more finely tuned through cross-regulation with other regulatory pathways. Such crosstalk between regulatory pathways can lead to tighter regulation of type 1 fimbriae, and adds another layer to the complexity of type 1 fimbriae regulation. Finally, during an infection, pathogenic strains of E. coli are likely to be in a less than optimal environment within the host tissues [200]. Therefore, stress signals present within the host environment and immune defense responses can influence bacterial gene regulation, and phase variation of fimbriae and adaptation to such stresses are an important mechanism linked to the virulence of pathogenic E. coli. Differential and coordinated expression of fimbrial adhesins provides bacteria with the ability to shift receptor target affinity and therefore, change tissue preference. Moreover, we must highlight the importance of the specific strain and the type of infection it is associated with. Depending on whether the strain in question is an APEC, UPEC, or NMEC, the regulation of type 1 fimbriae can differ and therefore, the effect of environmental stress on type 1 fimbriae regulation can also be distinct depending on the host species and type of infection. Moreover, considering the regulatory crosstalk within different systems (between type 1 fimbriae, P fimbriae, F1C fimbriae, flagella), the link of type 1 fimbriae/virulence and stress is even more difficult to identify, but nevertheless interesting to study.

Through this review, we sought to present information supporting the important connection between stress responses and the expression of type 1 fimbriae. Concrete examples were highlighted including direct regulators of both stress and type 1 fimbrial expression such as ppGpp, LrhA, RpoS, or cAMP. Interestingly, type 1 fimbriae appear to be an alert signal for the bacteria of certain environmental disorders as its expression is influenced by genes implicated in stress responses. In numerous cases, as highlighted above concerning treA, the TCS Cpx, or OmpA, the precise link between regulation of 
stress and type 1 fimbriae remains to be elucidated. At this point, the direct interactions leading to changes in type 1 regulation that are dependent on these systems remain to be discovered, but the attenuation of virulence observed in mutants could be explained by a complex and indirect regulation of type 1 fimbriae through a number of stress regulators, resulting in a decreased expression of type 1 fimbriae.

\section{Perspectives and Outstanding Questions}

Further insight into the regulatory mechanisms controlling the expression of type 1 fimbriae could provide a means to identify cues to inhibit the expression of fimbriae and other virulence factors, leading to novel avenues to treat or prevent such infections. For now, knock-out or deletion mutants are commonly used to investigate gene function in bacteria. However, this method cannot be applied to genes that are essential for cell growth. An alternative approach would be to conditionally silence the gene, knocking down its expression, without altering the genome. Using knock-down mutants through antisense RNA methods would provide a more transient and refined model to study the regulatory pathway of type 1 fimbriae under different growth conditions. This method is performed by the expression of an antisense RNA which binds and leads to degradation of its target mRNA, leading to decreased gene product. Gene knock-down can be complete or partial. In E. coli, knock-down experiments have already been done [201-203] and this would be an interesting avenue of research to pursue. Thus far, the phenomenon of phase variation of type 1 fimbriae has mainly been investigated in the context of a global population of multiple bacterial cells. With newer approaches and technologies now available to investigate single-cell gene expression and adaptation, it will be of interest to determine mechanisms of regulation and regulation of the switching of the fim promoter switch at the single-cell level as well as within a population of E. coli cells.

\section{Glossary}

ABC transporter (ATP-Binding Cassette Transporter): A member of a ubiquitous superfamily of membrane-bound pumps present in all prokaryotes. Directional substrate transport across a membrane bilayer is achieved by an ATP-dependent flipping mecha-nism from an inward- to an outward-facing conformation.

Adhesin: The surface-exposed bacterial molecule that mediates specific binding to a receptor or ligand on a target cell.

Biofilm: A community of cells that are attached to a surface or interface or to each other, and are imbedded in a self-made, protective matrix of extracellular polymeric sub-stances that are protected from immune responses, antimicrobial agents, and other stresses.

CCR (Carbon Catabolite Repression): A regulatory phenomenon by which the expression of functions for the use of secondary carbon sources and the activities of the cor-responding enzymes are reduced in the presence of a preferred carbon source.

CUP (Chaperone Usher Pathway): A system that facilitates the folding, transport and ordered assembly of fimbriae subunits at the cell surface.

Fimbriae: Long non-flagellar appendages at the cell surface, also referred to as pili, that are present in a wide range of Gram-negative and Gram-positive bacteria and in ar-chaea, and are involved in bacterial attachment.

Curli: Extracellular amyloid-like protein fibres produced by some bacteria, which are involved in adhesion, biofilm formation, and surface colonization.

HSR (Heat Shock Response): A response which involves the induction of expression of a large number of proteins upon increases in temperature.

IBC (Intracellular Bacterial Communities): Uropathogenic Escherichia coli (UPEC) biofilm-like intracellular bacterial communities formed by uropathogenic Escherichia coli that protect their members from the immune system, antibiotics, and other stresses.

Iron requirement: One of the most important types of nutrient limitation in the host environment is metal limitation. 
Nutritional immunity: Sequestration of metals by the host immune system, leading to nutrient-limited environments that antagonize bacterial survival.

SecYEG translocon: A conserved machinery that mediates the translocation of proteins across biological membranes and into different cellular compartments.

Shear stress: Forces that are applied tangentially to a body's surface, generally generated by flow.

Author Contributions: Conceptualization, H.B.; formal analysis, H.B., C.A., and J.S.; writing—review and editing, H.B., C.A., J.S., and C.M.D.; visualization, J.S. and H.B.; supervision, C.M.D.; funding acquisition, C.M.D. All authors have read and agreed to the published version of the manuscript.

Funding: Funding for this work was supported by Natural Science and Engineering Research Council of Canada (NSERC) (https:/ / www.nserc-crsng.gc.ca) (Discovery program, project 2019-06642) and funding from the CRIPA, FRQ-NT center of research excellence.

Institutional Review Board Statement: Not applicable.

Informed Consent Statement: Not applicable.

Conflicts of Interest: The authors declare no conflict of interest.

\section{References}

1. Gottesman, S. Trouble is coming: Signaling pathways that regulate general stress responses in bacteria. J. Biol. Chem. 2019, 294, 11685-11700. [CrossRef] [PubMed]

2. Moriel, D.G.; Rosini, R.; Seib, K.; Serino, L.; Pizza, M.; Rappuoli, R. Escherichia coli: Great Diversity around a Common Core. mBio 2012, 3, e00118-12. [CrossRef] [PubMed]

3. Manges, A.R.; Geum, H.M.; Guo, A.; Edens, T.J.; Fibke, C.D.; Pitout, J.D.D. Global Extraintestinal Pathogenic Escherichia coli (ExPEC) Lineages. Clin. Microbiol. Rev. 2019, 32, e00135-18. [CrossRef]

4. Kaper, J.B.; Nataro, J.P.; Mobley, H. Pathogenic Escherichia coli. Nat. Rev. Genet. 2004, 2, 123-140. [CrossRef] [PubMed]

5. Alteri, C.J.; Mobley, H. Escherichia coli physiology and metabolism dictates adaptation to diverse host microenvironments. Curr. Opin. Microbiol. 2012, 15, 3-9. [CrossRef] [PubMed]

6. La Ragione, R.; Woodward, M. Virulence factors of Escherichia coli serotypes associated with avian colisepticaemia. Res. Veter- Sci. 2002, 73, 27-35. [CrossRef]

7. Johnson, J.R.; Russo, T.A. Extraintestinal pathogenic Escherichia coli: “The other bad E. coli”. J. Lab. Clin. Med. 2002, 139, 155-162. [CrossRef] [PubMed]

8. Smith, J.L.; Fratamico, P.M.; Gunther, N.W. Extraintestinal Pathogenic Escherichia coli. Foodborne Pathog. Dis. 2007, 4, 134-163. [CrossRef]

9. Lindstedt, B.-A.; Finton, M.D.; Porcellato, D.; Brandal, L.T. High frequency of hybrid Escherichia coli strains with combined Intestinal Pathogenic Escherichia coli (IPEC) and Extraintestinal Pathogenic Escherichia coli (ExPEC) virulence factors isolated from human faecal samples. BMC Infect. Dis. 2018, 18, 544. [CrossRef]

10. Denamur, E.; Clermont, O.; Bonacorsi, S.; Gordon, D. The population genetics of pathogenic Escherichia coli. Nat. Rev. Genet. 2020, 19, 37-54. [CrossRef]

11. Sarowska, J.; Futoma-Koloch, B.; Jama-Kmiecik, A.; Frej-Madrzak, M.; Ksiazczyk, M.; Bugla-Ploskonska, G.; Choroszy-Krol, I. Virulence factors, prevalence and potential transmission of extraintestinal pathogenic Escherichia coli isolated from different sources: Recent reports. Gut Pathog. 2019, 11, 10. [CrossRef]

12. Welch, R.A.; Burland, V.; Plunkett, G.; Redford, P.; Roesch, P.; Rasko, D.; Buckles, E.L.; Liou, S.R.; Boutin, A.; Hackett, J.; et al. Extensive mosaic structure revealed by the complete genome sequence of uropathogenic Escherichia coli. Proc. Natl. Acad. Sci. USA 2002, 99, 17020-17024. [CrossRef]

13. Dobrindt, U.; Chowdary, M.G.; Krumbholz, G.; Hacker, J. Genome dynamics and its impact on evolution of Escherichia coli. Med. Microbiol. Immunol. 2010, 199, 145-154. [CrossRef]

14. Klemm, P.; Hancock, V.; Schembri, M.A. Fimbrial adhesins from extraintestinal Escherichia coli. Environ. Microbiol. Rep. 2010, 2, 628-640. [CrossRef]

15. Spurbeck, R.R.; Stapleton, A.; Johnson, J.R.; Walk, S.T.; Hooton, T.M.; Mobley, H.L.T. Fimbrial Profiles Predict Virulence of Uropathogenic Escherichia coli Strains: Contribution of Ygi and Yad Fimbriae. Infect. Immun. 2011, 79, 4753-4763. [CrossRef]

16. Nowicki, B.; Rhen, M.; Väisänen-Rhen, V.; Pere, A.; Korhonen, T.K. Immunofluorescence study of fimbrial phase variation in Escherichia coli KS71. J. Bacteriol. 1984, 160, 691-695. [CrossRef]

17. Snyder, J.A.; Haugen, B.J.; Lockatell, C.V.; Maroncle, N.; Hagan, E.C.; Johnson, D.E.; Welch, R.A.; Mobley, H.L.T. Coordinate Expression of Fimbriae in Uropathogenic Escherichia coli. Infect. Immun. 2005, 73, 7588-7596. [CrossRef]

18. Epler Barbercheck, C.R.; Bullitt, E.; Andersson, M. Bacterial adhesion pili. In Membrane Protein Complexes: Structure and Function; Harris, J.R., Boekema, E.J., Eds.; Springer: Singapore, 2018; Volume 87, pp. 1-18. 
19. Ottow, J.C.G. Ecology, physiology, and genetics of fimbriae and pili. Annu. Rev. Microbiol. 1975, 29, 79-108. [CrossRef]

20. Flores-Mireles, A.L.; Walker, J.N.; Caparon, M.G.; Hultgren, S.J. Urinary tract infections: Epidemiology, mechanisms of infection and treatment options. Nat. Rev. Microbiol. 2015, 13, 269-284. [CrossRef]

21. Teng, C.-H.; Cai, M.; Shin, S.; Xie, Y.; Kim, K.-J.; Khan, N.A.; Di Cello, F.; Kim, K.S. Escherichia coli K1 RS218 Interacts with Human Brain Microvascular Endothelial Cells via Type 1 Fimbria Bacteria in the Fimbriated State. Infect. Immun. 2005, 73, 2923-2931. [CrossRef]

22. Pourbakhsh, S.A.; Boulianne, M.; Martineau-Doize, B.; Dozois, C.M.; Desautels, C.; Fairbrother, J.M. Dynamics of Escherichia coli Infection in Experimentally Inoculated Chickens. Avian Dis. 1997, 41, 221. [CrossRef]

23. Dozois, C.M.; Chanteloup, N.; Dho-Moulin, M.; Bree, A.; Desautels, C.; Fairbrother, J.M. Bacterial Colonization and in vivo Expression of F1 (Type 1) Fimbrial Antigens in Chickens Experimentally Infected with Pathogenic Escherichia coli. Avian Dis. 1994, 38, 231. [CrossRef]

24. Fronzes, R.; Remaut, H.; Waksman, G. Architectures and biogenesis of non-flagellar protein appendages in Gram-negative bacteria. EMBO J. 2008, 27, 2271-2280. [CrossRef]

25. Soto, G.E.; Hultgren, S.J. Bacterial Adhesins: Common Themes and Variations in Architecture and Assembly. J. Bacteriol. 1999, 181, 1059-1071. [CrossRef] [PubMed]

26. Busch, A.; Waksman, G. Chaperone-usher pathways: Diversity and pilus assembly mechanism. Philos. Trans. R. Soc. B Biol. Sci. 2012, 367, 1112-1122. [CrossRef] [PubMed]

27. Jones, C.H.; Danese, P.N.; Pinkner, J.S.; Silhavy, T.; Hultgren, S.J. The chaperone-assisted membrane release and folding pathway is sensed by two signal transduction systems. EMBO J. 1997, 16, 6394-6406. [CrossRef] [PubMed]

28. Chahales, P.; Thanassi, D.G. Structure, Function, and Assembly of Adhesive Organelles by Uropathogenic Bacteria. Microbiol. Spectr. 2015, 3, 3-5. [CrossRef]

29. Pan, K.-L.; Hsiao, H.-C.; Weng, C.-L.; Wu, M.-S.; Chou, C.P. Roles of DegP in Prevention of Protein Misfolding in the Periplasm upon Overexpression of Penicillin Acylase in Escherichia coli. J. Bacteriol. 2003, 185, 3020-3030. [CrossRef]

30. Klemm, P.; Jørgensen, B.J.; Van Die, I.; De Ree, H.; Bergmans, H. The fim genes responsible for synthesis of type 1 fimbriae in Escherichia coli, cloning and genetic organization. Mol. Genet. Genom. 1985, 199, 410-414. [CrossRef]

31. Klemm, P. Two regulatory fim genes, fimB and fimE, control the phase variation of type 1 fimbriae in Escherichia coli. EMBO J. 1986, 5, 1389-1393. [CrossRef]

32. Orndorff, P.E.; Falkow, S. Organization and expression of genes responsible for type 1 piliation in Escherichia coli. J. Bacteriol. 1984, 159, 736-744. [CrossRef]

33. Jones, C.H.; Pinkner, J.; Roth, R.; Heuser, J.; Nicholes, A.V.; Abraham, S.N.; Hultgren, S.J. FimH adhesin of type 1 pili is assembled into a fibrillar tip structure in the Enterobacteriaceae. Proc. Natl. Acad. Sci. USA 1995, 92, 2081-2085. [CrossRef] [PubMed]

34. Abraham, J.M.; Freitag, C.S.; Clements, J.R.; Eisenstein, B.I. An invertible element of DNA controls phase variation of type 1 fimbriae of Escherichia coli. Proc. Natl. Acad. Sci. USA 1985, 82, 5724-5727. [CrossRef]

35. Klemm, P.; Christiansen, G. Three fim genes required for the regulation of length and mediation of adhesion of Escherichia coli type 1 fimbriae. Mol. Genet. Genom. 1987, 208, 439-445. [CrossRef]

36. Abraham, S.N.; Goguen, J.D.; Sun, D.; Klemm, P.; Beachey, E.H. Identification of two ancillary subunits of Escherichia coli type 1 fimbriae by using antibodies against synthetic oligopeptides of fim gene products. J. Bacteriol. 1987, 169, 5530-5536. [CrossRef]

37. Valenski, M.L.; Harris, S.L.; Spears, P.A.; Horton, J.R.; Orndorff, P.E. The Product of the fimI Gene Is Necessary for Escherichia coli Type 1 Pilus Biosynthesis. J. Bacteriol. 2003, 185, 5007-5011. [CrossRef]

38. Gally, D.L.; Leathart, J.; Blomfield, I.C. Interaction of FimB and FimE with thefimswitch that controls the phase variation of type 1 fimbriae in Escherichia coli K-12. Mol. Microbiol. 1996, 21, 725-738. [CrossRef]

39. Giampapa, C.S.; Abraham, S.N.; Chiang, T.M.; Beachey, E.H. Isolation and characterization of a receptor for type 1 fimbriae of Escherichia coli from guinea pig erythrocytes. J. Biol. Chem. 1988, 263, 5362-5367. [CrossRef]

40. Gottesman, S. Stress Reduction, Bacterial Style. J. Bacteriol. 2017, 199, e00433-17. [CrossRef]

41. Hengge-Aronis, R. Back to log phase: $\sigma \mathrm{S}$ as a global regulator in the osmotic control of gene expression in Escherichia coli. Mol. Microbiol. 1996, 21, 887-893. [CrossRef]

42. Soutourina, O.; Kolb, A.; Krin, E.; Laurent-Winter, C.; Rimsky, S.; Danchin, A.; Bertin, P. Multiple Control of Flagellum Biosynthesis in Escherichia coli: Role of H-NS Protein and the Cyclic AMP-Catabolite Activator Protein Complex in Transcription of the flhDC Master Operon. J. Bacteriol. 1999, 181, 7500-7508. [CrossRef] [PubMed]

43. Roesch, P.L.; Blomfield, I.C. Leucine alters the interaction of the leucine-responsive regulatory protein (Lrp) with thefimswitch to stimulate site-specific recombination in Escherichia coli. Mol. Microbiol. 1998, 27, 751-761. [CrossRef] [PubMed]

44. Dalebroux, Z.D.; Svensson, S.L.; Gaynor, E.C.; Swanson, M.S. ppGpp Conjures Bacterial Virulence. Microbiol. Mol. Biol. Rev. 2010, 74, 171-199. [CrossRef]

45. Lemke, J.J.; Durfee, T.; Gourse, R.L. DksA and ppGpp directly regulate transcription of the Escherichia coli flagellar cascade. Mol. Microbiol. 2009, 74, 1368-1379. [CrossRef]

46. Foster, J.W. Escherichia coli acid resistance: Tales of an amateur acidophile. Nat. Rev. Genet. 2004, 2, 898-907. [CrossRef]

47. Johnson, J.R.; Clabots, C.; Rosen, H. Effect of Inactivation of the Global Oxidative Stress Regulator oxyR on the Colonization Ability of Escherichia coli O1:K1:H7 in a Mouse Model of Ascending Urinary Tract Infection. Infect. Immun. 2006, 74, 461-468. [CrossRef] 
48. Hung, D.L.; Raivio, T.; Jones, C.; Silhavy, T.; Hultgren, S.J. Cpx signaling pathway monitors biogenesis and affects assembly and expression of P pili. EMBO J. 2001, 20, 1508-1518. [CrossRef]

49. Andersen, J.; Forst, S.A.; Zhao, K.; Inouye, M.; Delihas, N. The function of micF RNA. J. Biol. Chem. 1989, 264, 17961-17970. [CrossRef]

50. Porcheron, G.; Habib, R.; Houle, S.; Caza, M.; Lépine, F.; Daigle, F.; Massé, E.; Dozois, C.M. The Small RNA RyhB Contributes to Siderophore Production and Virulence of Uropathogenic Escherichia coli. Infect. Immun. 2014, 82, 5056-5068. [CrossRef]

51. Opdyke, J.A.; Kang, J.-G.; Storz, G. GadY, a Small-RNA Regulator of Acid Response Genes in Escherichia coli. J. Bacteriol. 2004, 186, 6698-6705. [CrossRef]

52. Bessaiah, H.; Pokharel, P.; Loucif, H.; Kulbay, M.; Sasseville, C.; Habouria, H.; Houle, S.; Bernier, J.; Massé, E.; Van Grevenynghe, J.; et al. The RyfA small RNA regulates oxidative and osmotic stress responses and virulence in uropathogenic Escherichia coli. PLoS Pathog. 2021, 17, e1009617. [CrossRef] [PubMed]

53. Nonaka, G.; Blankschien, M.; Herman, C.; Gross, C.A.; Rhodius, V.A. Regulon and promoter analysis of the E. coli heat-shock factor, $\sigma 32$, reveals a multifaceted cellular response to heat stress. Genes Dev. 2006, 20, 1776-1789. [CrossRef] [PubMed]

54. De Biase, D.; Tramonti, A.; Bossa, F.; Visca, P. The response to stationary-phase stress conditions in Escherichia coli: Role and regulation of the glutamic acid decarboxylase system. Mol. Microbiol. 1999, 32, 1198-1211. [CrossRef] [PubMed]

55. Kolter, R.; Siegele, D.A.; Tormo, A. The stationary phase of the bacterial life cycle. Annu. Rev. Microbiol. 1993, 47, 855-874. [CrossRef]

56. Gruber, T.M.; Gross, C.A. Multiple Sigma Subunits and the Partitioning of Bacterial Transcription Space. Annu. Rev. Microbiol. 2003, 57, 441-466. [CrossRef]

57. Brown, L.; Gentry, D.; Elliott, T.; Cashel, M. DksA Affects ppGpp Induction of RpoS at a Translational Level. J. Bacteriol. 2002, 184, 4455-4465. [CrossRef]

58. Kvint, K.; Farewell, A.; Nyström, T. RpoS-dependent Promoters Require Guanosine Tetraphosphate for Induction Even in the Presence of High Levels of $\varsigma$ s. J. Biol. Chem. 2000, 275, 14795-14798. [CrossRef]

59. Girard, M.E.; Gopalkrishnan, S.; Grace, E.D.; Halliday, J.A.; Gourse, R.L.; Herman, C. DksA and ppGpp Regulate the $\sigma$ S Stress Response by Activating Promoters for the Small RNA DsrA and the Anti-Adapter Protein IraP. J. Bacteriol. 2018, 200. [CrossRef]

60. Schellhorn, H.E.; Hassan, H.M. Transcriptional regulation of katE in Escherichia coli K-12. J. Bacteriol. 1988, 170, 4286-4292. [CrossRef]

61. Hryckowian, A.J.; Welch, R.A. RpoS Contributes to Phagocyte Oxidase-Mediated Stress Resistance during Urinary Tract Infection by Escherichia coli CFT073. mBio 2013, 4, e00023-13. [CrossRef]

62. Tramonti, A.; Visca, P.; De Canio, M.; Falconi, M.; De Biase, D. Functional Characterization and Regulation of gadX, a Gene Encoding an AraC/XylS-Like Transcriptional Activator of the Escherichia coli Glutamic Acid Decarboxylase System. J. Bacteriol. 2002, 184, 2603-2613. [CrossRef]

63. Sommerfeldt, N.; Possling, A.; Becker, G.; Pesavento, C.; Tschowri, N.; Hengge, R. Gene expression patterns and differential input into curli fimbriae regulation of all GGDEF/EAL domain proteins in Escherichia coli. Microbiology 2009, 155, 1318-1331. [CrossRef]

64. Kulesus, R.R.; Diaz-Perez, K.; Slechta, E.S.; Eto, D.S.; Mulvey, M.A. Impact of the RNA Chaperone Hfq on the Fitness and Virulence Potential of Uropathogenic Escherichia coli. Infect. Immun. 2008, 76, 3019-3026. [CrossRef]

65. Dong, T.; Schellhorn, H.E. Role of RpoS in Virulence of Pathogens. Infect. Immun. 2010, 78, 887-897. [CrossRef]

66. Dove, S.L.; Smith, S.; Dorman, C. Control of Escherichia coli type 1 fimbrial gene expression in stationary phase: A negative role for RpoS. Mol. Genet. Genom. 1997, 254, 13-20. [CrossRef]

67. Aberg, A.; Shingler, V.; Balsalobre, C. (p)ppGpp regulates type 1 fimbriation of Escherichia coli by modulating the expression of the site-specific recombinase FimB. Mol. Microbiol. 2006, 60, 1520-1533. [CrossRef]

68. Müller, C.M.; Åberg, A.; Straseviçiene, J.; Emődy, L.; Uhlin, B.E.; Balsalobre, C. Type 1 Fimbriae, a Colonization Factor of Uropathogenic Escherichia coli, Are Controlled by the Metabolic Sensor CRP-cAMP. PLoS Pathog. 2009, 5, e1000303. [CrossRef]

69. Zhou, Y.; Gottesman, S. Modes of Regulation of RpoS by H-NS. J. Bacteriol. 2006, 188, 7022-7025. [CrossRef]

70. Blomfield, I.C.; Kulasekara, D.H.; Eisenstein, B.I. Integration host factor stimulates both FimB- and FimE-mediated site-specific DNA inversion that controls phase variation of type 1 fimbriae expression in Escherichia coli. Mol. Microbiol. 1997, 23, 705-707. [CrossRef]

71. Gally, D.; Bogan, J.A.; Eisenstein, B.I.; Blomfield, I.C. Environmental regulation of the fim switch controlling type 1 fimbrial phase variation in Escherichia coli K-12: Effects of temperature and media. J. Bacteriol. 1993, 175, 6186-6193. [CrossRef]

72. Olsen, P.B.; Schembri, M.A.; Gally, D.L.; Klemm, P. Differential temperature modulation by H-NS of thefimBandfimErecombinase genes which control the orientation of the type 1 fimbrial phase switch. FEMS Microbiol. Lett. 1998, 162, 17-23. [CrossRef]

73. Blumer, C.; Kleefeld, A.; Lehnen, D.; Heintz, M.; Dobrindt, U.; Nagy, G.; Michaelis, K.; Emödy, L.; Polen, T.; Rachel, R.; et al. Regulation of type 1 fimbriae synthesis and biofilm formation by the transcriptional regulator LrhA of Escherichia coli. Microbiology 2005, 151, 3287-3298. [CrossRef]

74. Matter, L.B.; Ares, M.; Abundes-Gallegos, J.; Cedillo, M.L.; Yáñez, J.A.; Martínez-Laguna, Y.; De la Cruz, M.A.; Girón, J.A. The CpxRA stress response system regulates virulence features of avian pathogenic Escherichia coli. Environ. Microbiol. 2018, 20, 3363-3377. [CrossRef]

75. Herren, C.D.; Mitra, A.; Palaniyandi, S.K.; Coleman, A.; Elankumaran, S.; Mukhopadhyay, S. The BarA-UvrY Two-Component System Regulates Virulence in Avian Pathogenic Escherichia coli O78:K80:H9. Infect. Immun. 2006, 74, 4900-4909. [CrossRef] 
76. Pavanelo, D.; Houle, S.; Matter, L.B.; Dozois, C.M.; Horn, F. The Periplasmic Trehalase Affects Type 1 Fimbria Production and Virulence of Extraintestinal Pathogenic Escherichia coli Strain MT78. Infect. Immun. 2018, 86, e00241-18. [CrossRef]

77. Conover, M.S.; Hadjifrangiskou, M.; Palermo, J.J.; Hibbing, M.E.; Dodson, K.W.; Hultgren, S.J. Metabolic Requirements of Escherichia coli in Intracellular Bacterial Communities during Urinary Tract Infection Pathogenesis. mBio 2016, 7, e00104-16. [CrossRef]

78. Cortes, M.A.M.; Gibon, J.; Chanteloup, N.K.; Moulin-Schouleur, M.; Gilot, P.; Germon, P. Inactivation of ibeA and ibeT Results in Decreased Expression of Type 1 Fimbriae in Extraintestinal Pathogenic Escherichia coli Strain BEN2908. Infect. Immun. 2008, 76, 4129-4136. [CrossRef]

79. Bessaiah, H.; Pokharel, P.; Habouria, H.; Houle, S.; Dozois, C.M. yqhG Contributes to Oxidative Stress Resistance and Virulence of Uropathogenic Escherichia coli and Identification of Other Genes Altering Expression of Type 1 Fimbriae. Front. Cell. Infect. Microbiol. 2019, 9, 312. [CrossRef]

80. Bateman, S.L.; Seed, P.C. Epigenetic regulation of the nitrosative stress response and intracellular macrophage survival by extraintestinal pathogenic Escherichia coli. Mol. Microbiol. 2012, 83, 908-925. [CrossRef]

81. Crépin, S.; Houle, S.; Charbonneau, M.; Mourez, M.; Harel, J.; Dozois, C.M. Decreased Expression of Type 1 Fimbriae by apstMutant of Uropathogenic Escherichia coli Reduces Urinary Tract Infection. Infect. Immun. 2012, 80, 2802-2815. [CrossRef]

82. Rouquet, G.; Porcheron, G.; Barra, C.; Reépeérant, M.; Chanteloup, N.K.; Schouler, C.; Gilot, P. A Metabolic Operon in Extraintestinal Pathogenic Escherichia coli Promotes Fitness under Stressful Conditions and Invasion of Eukaryotic Cells. J. Bacteriol. 2009, 191, 4427-4440. [CrossRef] [PubMed]

83. Kurabayashi, K.; Agata, T.; Asano, H.; Tomita, H.; Hirakawa, H. Fur Represses Adhesion to, Invasion of, and Intracellular Bacterial Community Formation within Bladder Epithelial Cells and Motility in Uropathogenic Escherichia coli. Infect. Immun. 2016, 84, 3220-3231. [CrossRef] [PubMed]

84. Eberly, A.R.; Floyd, K.; Beebout, C.; Colling, S.J.; Fitzgerald, M.J.; Stratton, C.W.; Schmitz, J.E.; Hadjifrangiskou, M. Biofilm Formation by Uropathogenic Escherichia coli Is Favored under Oxygen Conditions That Mimic the Bladder Environment. Int. J. Mol. Sci. 2017, 18, 2077. [CrossRef] [PubMed]

85. Vila, J.; Soto, S.M. Salicylate increases the expression of marA and reduces in vitro biofilm formation in uropathogenic Escherichia coli by decreasing type 1 fimbriae expression. Virulence 2012, 3, 280-285. [CrossRef]

86. Kostakioti, M.; Hadjifrangiskou, M.; Pinkner, J.S.; Hultgren, S.J. QseC-mediated dephosphorylation of QseB is required for expression of genes associated with virulence in uropathogenic Escherichia coli. Mol. Microbiol. 2009, 73, 1020-1031. [CrossRef]

87. Gibson, K.E.; Silhavy, T.J. The LysR Homolog LrhA Promotes RpoS Degradation by Modulating Activity of the Response Regulator SprE. J. Bacteriol. 1999, 181, 563-571. [CrossRef]

88. Brandi, A.; Giangrossi, M.; Fabbretti, A.; Falconi, M. The hns Gene of Escherichia coli Is Transcriptionally Down-Regulated by (p)ppGpp. Microorganisms 2020, 8, 1558. [CrossRef]

89. Dorman, C.J. H-NS, the genome sentinel. Nat. Rev. Genet. 2006, 5, 157-161. [CrossRef]

90. Atlung, T.; Ingmer, H. H-NS: A modulator of environmentally regulated gene expression. Mol. Microbiol. 1997, 24, 7-17. [CrossRef]

91. Williams, R.M.; Rimsky, S. Molecular aspects of the E. coli nucleoid protein, H-NS: A central controller of gene regulatory networks. FEMS Microbiol. Lett. 1997, 156, 175-185. [CrossRef]

92. Bertin, P.; Hommais, F.; Krin, E.; Soutourina, O.; Tendeng, C.; Derzelle, S.; Danchin, A. H-NS and H-NS-like proteins in Gram-negative bacteria andtheir multiple role in the regulation of bacterial metabolism. Biochimie 2001, 83, 235-241. [CrossRef]

93. Krin, E.; Danchin, A.; Soutourina, O. Decrypting the H-NS-dependent regulatory cascade of acid stress resistance in Escherichia coli. BMC Microbiol. 2010, 10, 1-9. [CrossRef]

94. Hommais, F.; Krin, E.; Laurent-Winter, C.; Soutourina, O.; Malpertuy, A.; Le Caer, J.-P.; Danchin, A.; Bertin, P. Large-scale monitoring of pleiotropic regulation of gene expression by the prokaryotic nucleoid-associated protein, H-NS. Mol. Microbiol. 2001, 40, 20-36. [CrossRef]

95. Johansson, J.; Uhlin, B.E. Differential protease-mediated turnover of H-NS and StpA revealed by a mutation altering protein stability and stationary-phase survival of Escherichia coli. Proc. Natl. Acad. Sci. USA 1999, 96, 10776-10781. [CrossRef]

96. White-Ziegler, C.A.; Davis, T.R. Genome-Wide Identification of H-NS-Controlled, Temperature-Regulated Genes in Escherichia coli K-12. J. Bacteriol. 2009, 191, 1106-1110. [CrossRef]

97. Muüller, C.M.; Dobrindt, U.; Nagy, G.; Emoödy, L.; Uhlin, B.E.; Hacker, J. Role of Histone-Like Proteins H-NS and StpA in Expression of Virulence Determinants of Uropathogenic Escherichia coli. J. Bacteriol. 2006, 188, 5428-5438. [CrossRef]

98. White-Ziegler, C.A.; Hill, M.L.A.; Braaten, B.A.; van der Woude, M.W.; Low, D.A. Thermoregulation of Escherichia coli pap transcription: H-NS is a temperature-dependent DNA methylation blocking factor. Mol. Microbiol. 1998, 28, 1121-1137. [CrossRef]

99. Göransson, M.; Sondén, B.; Nilsson, P.; Dagberg, B.; Foreman, K.; Emanuelsson, K.; Uhlin, B.E. Transcriptional silencing and thermoregulation of gene expression in Escherichia coli. Nature 1990, 344, 682-685. [CrossRef]

100. Brambilla, E.; Sclavi, B. Gene Regulation by H-NS as a Function of Growth Conditions Depends on Chromosomal Position in Escherichia coli. G3 Genes Genomes Genet. 2015, 5, 605-614. [CrossRef]

101. Oshima, T.; Ito, K.; Kabayama, H.; Nakamura, Y. Regulation of Irp gene expression by H-NS and Lrp proteins in Escherichia coli: Dominant negative mutations in Irp. Mol. Genet. Genom. 1995, 247, 521-528. [CrossRef] 
102. Calvo, J.M.; Matthews, R.G. The leucine-responsive regulatory protein, a global regulator of metabolism in Escherichia coli. Microbiol. Rev. 1994, 58, 466-490. [CrossRef]

103. Ernsting, B.R.; Atkinson, M.R.; Ninfa, A.J.; Matthews, R.G. Characterization of the regulon controlled by the leucine-responsive regulatory protein in Escherichia coli. J. Bacteriol. 1992, 174, 1109-1118. [CrossRef]

104. Wang, Q.; Wu, J.; Friedberg, D.; Plakto, J.; Calvo, J.M. Regulation of the Escherichia coli lrp gene. J. Bacteriol. 1994, 176, 1831-1839. [CrossRef]

105. Blomfield, I.C.; Calie, P.J.; Eberhardt, K.J.; McClain, M.; Eisenstein, B.I. Lrp stimulates phase variation of type 1 fimbriation in Escherichia coli K-12. J. Bacteriol. 1993, 175, 27-36. [CrossRef]

106. Cho, B.-K.; Barrett, C.L.; Knight, E.M.; Park, Y.S.; Palsson, B. Genome-scale reconstruction of the Lrp regulatory network in Escherichia coli. Proc. Natl. Acad. Sci. USA 2008, 105, 19462-19467. [CrossRef]

107. Kroner, G.M.; Wolfe, M.B.; Freddolino, P.L. Escherichia coli Lrp Regulates One-Third of the Genome via Direct, Cooperative, and Indirect Routes. J. Bacteriol. 2019, 201, e00411-18. [CrossRef]

108. Newman, E.B.; Lin, R. Leucine-responsive regulatory protein: A Global Regulator of Gene Expression in E. Coli. Annu. Rev. Microbiol. 1995, 49, 747-775. [CrossRef]

109. Hart, B.R.; Blumenthal, R.M. Unexpected Coregulator Range for the Global Regulator Lrp of Escherichia coli and Proteus mirabilis. J. Bacteriol. 2011, 193, 1054-1064. [CrossRef]

110. Landgraf, J.R.; Wu, J.; Calvo, J.M. Effects of nutrition and growth rate on Lrp levels in Escherichia coli. J. Bacteriol. 1996, 178, 6930-6936. [CrossRef]

111. Lee, S.Y.; Lim, C.J.; Droge, P.; Yan, J. Regulation of Bacterial DNA Packaging in Early Stationary Phase by Competitive DNA Binding of Dps and IHF. Sci. Rep. 2015, 5, 18146. [CrossRef]

112. Neidhardt, F.C.; Curtiss, R. Escherichia coli and Salmonella: Cellular and Molecular Biology, ed., 2nd ed.; American Society for Micro-Biology: Washington, DC, USA, 1996.

113. Gourse, R.L.; Chen, A.Y.; Gopalkrishnan, S.; Sanchez-Vazquez, P.; Myers, A.; Ross, W. Transcriptional Responses to ppGpp and DksA. Annu. Rev. Microbiol. 2018, 72, 163-184. [CrossRef] [PubMed]

114. Sanchez-Vazquez, P.; Dewey, C.N.; Kitten, N.; Ross, W.; Gourse, R.L. Genome-wide effects on Escherichia coli transcription from ppGpp binding to its two sites on RNA polymerase. Proc. Natl. Acad. Sci. USA 2019, 116, 8310-8319. [CrossRef] [PubMed]

115. Abranches, J.; Martinez, A.R.; Kajfasz, J.K.; Chaévez, V.; Garsin, D.A.; Lemos, J.A. The Molecular Alarmone (p)ppGpp Mediates Stress Responses, Vancomycin Tolerance, and Virulence in Enterococcus faecalis. J. Bacteriol. 2009, 191, 2248-2256. [CrossRef] [PubMed]

116. Wells, D.H.; Gaynor, E.C. Helicobacter pylori Initiates the Stringent Response upon Nutrient and pH Downshift. J. Bacteriol. 2006, 188, 3726-3729. [CrossRef]

117. Gentry, D.R.; Hernandez, V.J.; Nguyen, L.H.; Jensen, D.B.; Cashel, M. Synthesis of the stationary-phase sigma factor sigma s is positively regulated by ppGpp. J. Bacteriol. 1993, 175, 7982-7989. [CrossRef]

118. Cashel, M.; Gallant, J. Two Compounds implicated in the Function of the RC Gene of Escherichia coli. Nature 1969, $221,838-841$. [CrossRef]

119. Gallant, J.A. Stringent control in E. coli. Annu. Rev. Genet. 1979, 13, 393-415. [CrossRef]

120. Godfrey, $\mathrm{H}$. The role of the stringent response in the pathogenesis of bacterial infections. Trends Microbiol. 2002, 10, 349-351. [CrossRef]

121. Magnusson, L.U.; Farewell, A.; Nyström, T. ppGpp: A global regulator in Escherichia coli. Trends Microbiol. 2005, 13, 236-242. [CrossRef]

122. Germain, E.; Guiraud, P.; Byrne, D.; Douzi, B.; Djendli, M.; Maisonneuve, E. YtfK activates the stringent response by triggering the alarmone synthetase SpoT in Escherichia coli. Nat. Commun. 2019, 10, 1-12. [CrossRef]

123. Traxler, M.F.; Summers, S.M.; Nguyen, H.-T.; Zacharia, V.M.; Hightower, G.A.; Smith, J.T.; Conway, T. The global, ppGpp-mediated stringent response to amino acid starvation in Escherichia coli. Mol. Microbiol. 2008, 68, 1128-1148. [CrossRef]

124. Durfee, T.; Hansen, A.-M.; Zhi, H.; Blattner, F.R.; Jin, D.J. Transcription Profiling of the Stringent Response in Escherichia coli. J. Bacteriol. 2008, 190, 1084-1096. [CrossRef]

125. Botsford, J.L.; Harman, J.G. Cyclic AMP in prokaryotes. Microbiol. Rev. 1992, 56, 100-122. [CrossRef]

126. McDonough, K.A.; Rodriguez, A. The myriad roles of cyclic AMP in microbial pathogens: From signal to sword. Nat. Rev. Genet. 2011, 10, 27-38. [CrossRef]

127. Kalia, D.; Merey, G.; Nakayama, S.; Zheng, Y.; Zhou, J.; Luo, Y.; Guo, M.; Roembke, B.T.; Sintim, H.O. Nucleotide, c-di-GMP, c-di-AMP, cGMP, cAMP, (p)ppGpp signaling in bacteria and implications in pathogenesis. Chem. Soc. Rev. 2012, 42, 305-341. [CrossRef]

128. Kolb, A.; Busby, S.; Buc, H.; Garges, S.; Adhya, S. Transcriptional regulation by camp and its receptor protein. Annu. Rev. Biochem. 1993, 62, 749-797. [CrossRef]

129. Görke, B.; Stülke, J. Carbon catabolite repression in bacteria: Many ways to make the most out of nutrients. Nat. Rev. Genet. 2008, 6, 613-624. [CrossRef]

130. Brã $\frac{1}{4}$ Ckner, R.; Titgemeyer, F. Carbon catabolite repression in bacteria: Choice of the carbon source and autoregulatory limitation of sugar utilization. FEMS Microbiol. Lett. 2002, 209, 141-148. [CrossRef] 
131. Fong, J.C.N.; Yildiz, F.H. Interplay between Cyclic AMP-Cyclic AMP Receptor Protein and Cyclic di-GMP Signaling in Vibrio cholerae Biofilm Formation. J. Bacteriol. 2008, 190, 6646-6659. [CrossRef]

132. Gosset, G.; Zhang, Z.; Nayyar, S.; Cuevas, W.A.; Saier, M.H. Transcriptome Analysis of Crp-Dependent Catabolite Control of Gene Expression in Escherichia coli. J. Bacteriol. 2004, 186, 3516-3524. [CrossRef]

133. Castanie-Cornet, M.-P.; Penfound, T.A.; Smith, D.; Elliott, J.F.; Foster, J.W. Control of Acid Resistance in Escherichia coli. J. Bacteriol. 1999, 181, 3525-3535. [CrossRef]

134. Barth, E.; Gora, K.V.; Gebendorfer, K.M.; Settele, F.; Jakob, U.; Winter, J. Interplay of cellular cAMP levels, $\sigma$ S activity and oxidative stress resistance in Escherichia coli. Microbiology 2009, 155, 1680-1689. [CrossRef]

135. Molina-Quiroz, R.C.; Silva, C.A.; Brewster, J.; Castro-Nallar, E.; Levy, S.B.; Camilli, A. Cyclic AMP Regulates Bacterial Persistence through Repression of the Oxidative Stress Response and SOS-Dependent DNA Repair in Uropathogenic Escherichia coli. mBio 2018, 9, e02144-17. [CrossRef]

136. Balsalobre, C.; Johansson, J.; Uhlin, B.E. Cyclic AMP-Dependent Osmoregulation of crp Gene Expression in Escherichia coli. J. Bacteriol. 2006, 188, 5935-5944. [CrossRef] [PubMed]

137. Ishizuka, H.; Hanamura, A.; Kunimura, T.; Aiba, H. A lowered concentration of cAMP receptor protein caused by glucose is an important determinant for catabolite repression in Escherichia coli. Mol. Microbiol. 1993, 10, 341-350. [CrossRef] [PubMed]

138. Hengge-Aronis, R. Signal Transduction and Regulatory Mechanisms Involved in Control of the $\sigma$ S (RpoS) Subunit of RNA Polymerase. Microbiol. Mol. Biol. Rev. 2002, 66, 373-395. [CrossRef] [PubMed]

139. Donovan, G.T.; Norton, J.P.; Bower, J.M.; Mulvey, M.A. Adenylate Cyclase and the Cyclic AMP Receptor Protein Modulate Stress Resistance and Virulence Capacity of Uropathogenic Escherichia coli. Infect. Immun. 2012, 81, 249-258. [CrossRef]

140. Holmqvist, E.; Wagner, E.G.H. Impact of bacterial sRNAs in stress responses. Biochem. Soc. Trans. 2017, 45, 1203-1212. [CrossRef]

141. Hoe, C.-H.; Raabe, C.A.; Rozhdestvensky, T.S.; Tang, T.-H. Bacterial sRNAs: Regulation in stress. Int. J. Med. Microbiol. 2013, 303, 217-229. [CrossRef]

142. Richards, G.R.; Vanderpool, C.K. Molecular call and response: The physiology of bacterial small RNAs. Biochim. Biophys. Acta (BBA) Bioenerg. 2011, 1809, 525-531. [CrossRef]

143. Fröhlich, K.S.; Gottesman, S. Small Regulatory RNAs in the Enterobacterial Response to Envelope Damage and Oxidative Stress. Microbiol. Spectr. 2018, 6, 211-228. [CrossRef]

144. Raghavan, R.; Groisman, E.A.; Ochman, H. Genome-wide detection of novel regulatory RNAs in E. coli. Genome Res. 2011, 21, 1487-1497. [CrossRef]

145. Masseé, E.; Vanderpool, C.K.; Gottesman, S. Effect of RyhB Small RNA on Global Iron Use in Escherichia coli. J. Bacteriol. 2005, 187, 6962-6971. [CrossRef]

146. Yuzawa, H.; Nagai, H.; Mori, H.; Yura, T. Heat induction of $\theta 32$ synthesis mediated by mRNA secondary structure: A primary step of the heat shock response in Escherichia coli. Nucleic Acids Res. 1993, 21, 5449-5455. [CrossRef]

147. Guisbert, E.; Yura, T.; Rhodius, V.A.; Gross, C.A. Convergence of Molecular, Modeling, and Systems Approaches for an Understanding of the Escherichia coli Heat Shock Response. Microbiol. Mol. Biol. Rev. 2008, 72, 545-554. [CrossRef]

148. Ritossa, F. Discovery of the heat shock response. Cell Stress Chaperones 1996, 1, 97-98. [CrossRef]

149. Bukau, B.; Horwich, A.L. The Hsp70 and Hsp60 Chaperone Machines. Cell 1998, 92, 351-366. [CrossRef]

150. Morimoto, R.I. Regulation of the heat shock transcriptional response: Cross talk between a family of heat shock factors, molecular chaperones, and negative regulators. Genes Dev. 1998, 12, 3788-3796. [CrossRef]

151. Guisbert, E.; Herman, C.; Lu, C.Z.; Gross, C.A. A chaperone network controls the heat shock response in E. coli. Genes Dev. 2004, 18, 2812-2821. [CrossRef]

152. Arsène, F.; Tomoyasu, T.; Bukau, B. The heat shock response of Escherichia coli. Int. J. Food Microbiol. 2000, 55, 3-9. [CrossRef]

153. Yamaguchi, Y.; Tomoyasu, T.; Takaya, A.; Morioka, M.; Yamamoto, T. Effects of disruption of heat shock genes on susceptibility of Escherichia coli to fluoroquinolones. BMC Microbiol. 2003, 3, 16. [CrossRef]

154. Silhavy, T.J.; Kahne, D.; Walker, S. The Bacterial Cell Envelope. Cold Spring Harb. Perspect. Biol. 2010, 2, a000414. [CrossRef]

155. Fang, F.C.; Frawley, E.R.; Tapscott, T.; Vázquez-Torres, A. Bacterial Stress Responses during Host Infection. Cell Host Microbe 2016, 20, 133-143. [CrossRef]

156. Raivio, T.L. MicroReview: Envelope stress responses and Gram-negative bacterial pathogenesis. Mol. Microbiol. 2005, 56, 1119-1128. [CrossRef]

157. Delhaye, A.; Collet, J.-F.; Laloux, G. A Fly on the Wall: How Stress Response Systems Can Sense and Respond to Damage to Peptidoglycan. Front. Cell. Infect. Microbiol. 2019, 9, 380. [CrossRef]

158. Hunke, S.; Keller, R.; Müller, V.S. Signal integration by the Cpx-envelope stress system. FEMS Microbiol. Lett. 2011, 326, 12-22. [CrossRef] [PubMed]

159. Raivio, T.L.; Leblanc, S.K.D.; Price, N.L. The Escherichia coli Cpx Envelope Stress Response Regulates Genes of Diverse Function That Impact Antibiotic Resistance and Membrane Integrity. J. Bacteriol. 2013, 195, 2755-2767. [CrossRef] [PubMed]

160. Landini, P. Cross-talk mechanisms in biofilm formation and responses to environmental and physiological stress in Escherichia coli. Res. Microbiol. 2009, 160, 259-266. [CrossRef] [PubMed]

161. Debnath, I.; Norton, J.P.; Barber, A.E.; Ott, E.M.; Dhakal, B.K.; Kulesus, R.R.; Mulvey, M.A. The Cpx Stress Response System Potentiates the Fitness and Virulence of Uropathogenic Escherichia coli. Infect. Immun. 2013, 81, 1450-1459. [CrossRef] [PubMed] 
162. Taschner, N.P.; Yagil, E.; Spira, B. A differential effect of $\sigma \mathrm{S}$ on the expression of the PHO regulon genes of Escherichia coli. Microbiology 2004, 150, 2985-2992. [CrossRef]

163. Teng, C.-H.; Xie, Y.; Shin, S.; Di Cello, F.; Paul-Satyaseela, M.; Cai, M.; Kim, K.S. Effects of ompA Deletion on Expression of Type 1 Fimbriae in Escherichia coli K1 Strain RS218 and on the Association of E. coli with Human Brain Microvascular Endothelial Cells. Infect. Immun. 2006, 74, 5609-5616. [CrossRef]

164. Miller, R.A.; Britigan, B.E. Role of oxidants in microbial pathophysiology. Clin. Microbiol. Rev. 1997, 10, 1-18. [CrossRef]

165. Fang, F.C. Antimicrobial reactive oxygen and nitrogen species: Concepts and controversies. Nat. Rev. Genet. 2004, 2, 820-832. [CrossRef]

166. Schwan, W.R.; Lee, J.L.; Lenard, F.A.; Matthews, B.T.; Beck, M.T. Osmolarity and pH Growth Conditions Regulate fim Gene Transcription and Type 1 Pilus Expression in Uropathogenic Escherichia coli. Infect. Immun. 2002, 70, 1391-1402. [CrossRef]

167. Snyder, J.A.; Haugen, B.J.; Buckles, E.L.; Lockatell, C.V.; Johnson, D.E.; Donnenberg, M.S.; Welch, R.A.; Mobley, H.L.T. Transcriptome of Uropathogenic Escherichia coli during Urinary Tract Infection. Infect. Immun. 2004, 72, 6373-6381. [CrossRef]

168. Withman, B.; Gunasekera, T.S.; Beesetty, P.; Agans, R.; Paliy, O. Transcriptional Responses of Uropathogenic Escherichia coli to Increased Environmental Osmolality Caused by Salt or Urea. Infect. Immun. 2012, 81, 80-89. [CrossRef]

169. Greene, S.E.; Hibbing, M.E.; Janetka, J.; Chen, S.; Hultgren, S.J. Human Urine Decreases Function and Expression of Type 1 Pili in Uropathogenic Escherichia coli. mBio 2015, 6, e00820-15. [CrossRef]

170. Greenberg, J.; Monach, P.; Chou, J.; Josephy, P.D.; Demple, B. Positive control of a global antioxidant defense regulon activated by superoxide-generating agents in Escherichia coli. Proc. Natl. Acad. Sci. USA 1990, 87, 6181-6185. [CrossRef]

171. Demple, B. Regulation of bacterial oxidative stress genes. Annu. Rev. Genet. 1991, 25, 315-337. [CrossRef]

172. Imlay, J.A. Cellular Defenses against Superoxide and Hydrogen Peroxide. Annu. Rev. Biochem. 2008, 77, 755-776. [CrossRef]

173. Zheng, M.; Storz, G. Redox sensing by prokaryotic transcription factors. Biochem. Pharmacol. 1999, 59, 1-6. [CrossRef]

174. Farr, S.B.; Kogoma, T. Oxidative stress responses in Escherichia coli and Salmonella typhimurium. Microbiol. Rev. 1991, 55, 561-585. [CrossRef]

175. Nunoshiba, T.; Hidalgo, E.; Cuevas, C.F.A.; Demple, B. Two-stage control of an oxidative stress regulon: The Escherichia coli SoxR protein triggers redox-inducible expression of the soxS regulatory gene. J. Bacteriol. 1992, 174, 6054-6060. [CrossRef] [PubMed]

176. Zheng, M.; Wang, X.; Templeton, L.J.; Smulski, D.R.; LaRossa, R.A.; Storz, G. DNA Microarray-Mediated Transcriptional Profiling of the Escherichia coli Response to Hydrogen Peroxide. J. Bacteriol. 2001, 183, 4562-4570. [CrossRef] [PubMed]

177. Chiang, S.M.; Schellhorn, H.E. Regulators of oxidative stress response genes in Escherichia coli and their functional conservation in bacteria. Arch. Biochem. Biophys. 2012, 525, 161-169. [CrossRef] [PubMed]

178. Lee, J.-H.; Lee, K.-L.; Yeo, W.-S.; Park, S.-J.; Roe, J.-H. SoxRS-Mediated Lipopolysaccharide Modification Enhances Resistance against Multiple Drugs in Escherichia coli. J. Bacteriol. 2009, 191, 4441-4450. [CrossRef] [PubMed]

179. Johnson, J.R.; Russo, T.A.; Drawz, S.M.; Clabots, C.; Olson, R.; Kuskowski, M.A.; Rosen, H. OxyR contributes to the virulence of a Clonal Group A Escherichia coli strain (O17:K+:H18) in animal models of urinary tract infection, subcutaneous infection, and systemic sepsis. Microb. Pathog. 2013, 64, 1-5. [CrossRef]

180. Fléchard, M.; Cortes, M.A.M.; Répérant, M.; Germon, P. New Role for the ibeA Gene in $\mathrm{H}_{2} \mathrm{O}_{2}$ Stress Resistance of Escherichia coli. J. Bacteriol. 2012, 194, 4550-4560. [CrossRef]

181. Hannan, T.J.; Mysorekar, I.U.; Chen, S.L.; Walker, J.N.; Jones, J.M.; Pinkner, J.S.; Hultgren, S.J.; Seed, P.C. LeuX tRNA-dependent and -independent mechanisms of Escherichia coli pathogenesis in acute cystitis. Mol. Microbiol. 2007, 67, 116-128. [CrossRef]

182. Bertrand, N.; Houle, S.; LeBihan, G.; Poirier, E.; Dozois, C.M.; Harel, J. Increased Pho Regulon Activation Correlates with Decreased Virulence of an Avian Pathogenic Escherichia coli O78 Strain. Infect. Immun. 2010, 78, 5324-5331. [CrossRef]

183. Lamarche, M.G.; Wanner, B.L.; Crépin, S.; Harel, J. The phosphate regulon and bacterial virulence: A regulatory network connecting phosphate homeostasis and pathogenesis. FEMS Microbiol. Rev. 2008, 32, 461-473. [CrossRef]

184. Crépin, S.; Lamarche, M.G.; Garneau, P.; Séguin, J.; Proulx, J.; Dozois, C.M.; Harel, J. Genome-wide transcriptional response of an avian pathogenic Escherichia coli (APEC) pst mutant. BMC Genom. 2008, 9, 568. [CrossRef]

185. Becker, K.; Skaar, E.P. Metal limitation and toxicity at the interface between host and pathogen. FEMS Microbiol. Rev. 2014, 38, 1235-1249. [CrossRef]

186. Klemm, P.; Schembri, M. Type 1 Fimbriae, Curli, and Antigen 43: Adhesion, Colonization, and Biofilm Formation. EcoSal Plus 2004, 1. [CrossRef]

187. Rasko, D.A.; Moreira, C.G.; Li, D.R.; Reading, N.C.; Ritchie, J.M.; Waldor, M.K.; Williams, N.; Taussig, R.; Wei, S.; Roth, M.; et al. Targeting QseC Signaling and Virulence for Antibiotic Development. Science 2008, 321, 1078-1080. [CrossRef]

188. Schwan, W.R.; Beck, M.T.; Hung, C.S.; Hultgren, S.J. Differential Regulation of Escherichia coli fimGenes following Binding to Mannose Receptors. J. Pathog. 2018, 2018, 1-8. [CrossRef]

189. Rentschler, A.E.; Lovrich, S.D.; Fitton, R.; Enos-Berlage, J.; Schwan, W.R. OmpR regulation of the uropathogenic Escherichia coli fimB gene in an acidic/high osmolality environment. Microbiology 2013, 159, 316-327. [CrossRef]

190. Tchesnokova, V.; Aprikian, P.; Kisiela, D.; Gowey, S.; Korotkova, N.; Thomas, W.; Sokurenko, E. Type 1 Fimbrial Adhesin FimH Elicits an Immune Response That Enhances Cell Adhesion of Escherichia coli. Infect. Immun. 2011, 79, 3895-3904. [CrossRef]

191. Ashkar, A.A.; Mossman, K.L.; Coombes, B.K.; Gyles, C.L.; Mackenzie, R. FimH Adhesin of Type 1 Fimbriae Is a Potent Inducer of Innate Antimicrobial Responses Which Requires TLR4 and Type 1 Interferon Signalling. PLoS Pathog. 2008, 4, e1000233. [CrossRef] 
192. Mian, M.F.; Lauzon, N.M.; Andrews, D.; Lichty, B.D.; Ashkar, A.A. FimH Can Directly Activate Human and Murine Natural Killer Cells via TLR4. Mol. Ther. 2010, 18, 1379-1388. [CrossRef]

193. Wang, L.; Keatch, R.; Zhao, Q.; Wright, J.A.; Bryant, C.E.; Redmann, A.L.; Terentjev, E.M. Influence of Type I Fimbriae and Fluid Shear Stress on Bacterial Behavior and Multicellular Architecture of Early Escherichia coli Biofilms at Single-Cell Resolution. Appl. Environ. Microbiol. 2018, 84, e02343-17. [CrossRef]

194. Thomas, W.E.; Nilsson, L.M.; Forero, M.; Sokurenko, E.V.; Vogel, V. Shear-dependent 'stick-and-roll' adhesion of type 1 fimbriated Escherichia coli. Mol. Microbiol. 2004, 53, 1545-1557. [CrossRef]

195. Eisenstein, B.I. Phase Variation of Type 1 Fimbriae in Escherichia coli Is Under Transcriptional Control. Science 1981, 214, 337-339. [CrossRef]

196. Sohanpal, B.K.; El-Labany, S.; Lahooti, M.; Plumbridge, J.A.; Blomfield, I.C. Integrated regulatory responses of fimB to Nacetylneuraminic (sialic) acid and GlcNAc in Escherichia coli K-12. Proc. Natl. Acad. Sci. USA 2004, 101, 16322-16327. [CrossRef]

197. Wu, Y.; Outten, F.W. IscR Controls Iron-Dependent Biofilm Formation in Escherichia coli by Regulating Type I Fimbria Expression. J. Bacteriol. 2009, 191, 1248-1257. [CrossRef]

198. McVicker, G.; Sun, L.; Sohanpal, B.K.; Gashi, K.; Williamson, R.A.; Plumbridge, J.; Blomfield, I.C. SlyA Protein Activates fimB Gene Expression and Type 1 Fimbriation in Escherichia coli K-12. J. Biol. Chem. 2011, 286, 32026-32035. [CrossRef]

199. Sohanpal, B.K.; Friar, S.; Roobol, J.; Plumbridge, J.A.; Blomfield, I.C. Multiple co-regulatory elements and IHF are necessary for the control of fimB expression in response to sialic acid and $\mathrm{N}$-acetylglucosamine in Escherichia coli K-12. Mol. Microbiol. 2007, 63, 1223-1236. [CrossRef]

200. Liu, Y.; Han, R.; Wang, J.; Yang, P.; Wang, F.; Yang, B. Magnesium Sensing Regulates Intestinal Colonization of Enterohemorrhagic Escherichia coli O157:H7. mBio 2020, 11, e02470-20. [CrossRef]

201. Nakashima, N.; Goh, S.; Good, L.; Tamura, T. Multiple-Gene Silencing Using Antisense RNAs in Escherichia coli; Springer: New York, NY, USA, 2011; pp. 307-319. [CrossRef]

202. Nakashima, N.; Tamura, T.; Good, L. Paired termini stabilize antisense RNAs and enhance conditional gene silencing in Escherichia coli. Nucleic Acids Res. 2006, 34, e138. [CrossRef]

203. Magistro, G.; Magistro, C.; Stief, C.G.; Schubert, S. A simple and highly efficient method for gene silencing in Escherichia coli. J. Microbiol. Methods 2018, 154, 25-32. [CrossRef] 